San Jose State University

SJSU ScholarWorks

Master's Theses

Master's Theses and Graduate Research

Fall 2013

\title{
Hydrogen/Deuterium Exchange Mass Spectrometry for the Study of Methanol-induced Conformational Transitions in Ubiquitin
}

Steven Raul Rocha

San Jose State University

Follow this and additional works at: https://scholarworks.sjsu.edu/etd_theses

\section{Recommended Citation}

Rocha, Steven Raul, "Hydrogen/Deuterium Exchange Mass Spectrometry for the Study of Methanolinduced Conformational Transitions in Ubiquitin" (2013). Master's Theses. 4402.

DOI: https://doi.org/10.31979/etd.2ve6-wnkm

https://scholarworks.sjsu.edu/etd_theses/4402

This Thesis is brought to you for free and open access by the Master's Theses and Graduate Research at SJSU ScholarWorks. It has been accepted for inclusion in Master's Theses by an authorized administrator of SJSU ScholarWorks. For more information, please contact scholarworks@sjsu.edu. 


\title{
HYDROGEN/DEUTERIUM EXCHANGE MASS SPECTROMETRY FOR THE STUDY OF METHANOL-INDUCED CONFORMATIONAL TRANSITIONS IN UBIQUITIN
}

\author{
A Thesis \\ Presented to \\ The Faculty of the Department of Chemistry \\ San José State University \\ In Partial Fulfillment \\ of the Requirements for the Degree \\ Master of Science
}

by

Steven Raul Rocha

December 2013 
(C) 2013

Steven R. Rocha

ALL RIGHTS RESERVED 
The Designated Thesis Committee Approves the Thesis Titled

\author{
HYDROGEN/DEUTERIUM EXCHANGE MASS SPECTROMETRY \\ FOR THE STUDY OF METHANOL-INDUCED \\ CONFORMATIONAL TRANSITIONS \\ IN UBIQUITIN \\ by \\ Steven Raul Rocha
}

APPROVED FOR THE DEPARTMENT OF CHEMISTRY

SAN JOSÉ STATE UNIVERSITY

December 2013
Dr. Daryl K. Eggers
Department of Chemistry
Dr. Lionel Cheruzel
Department of Chemistry
Dr. Brandon White
Department of Biological Sciences 


\section{ABSTRACT \\ HYDROGEN/DEUTERIUM EXCHANGE MASS SPECTROMETRY \\ FOR THE STUDY OF METHANOL-INDUCED \\ CONFORMATIONAL TRANSITIONS \\ IN UBIQUITIN}

In aqueous solutions with high concentrations of methanol at low $\mathrm{pH}$, the global conformation of ubiquitin denatures to a structure of increased helical character at $50 \%$ methanol to a highly helical denatured structure at $90 \%$ methanol. Circular dichroism analysis and hydrogen/deuterium exchange mass spectrometry experiments have been reported for the monitoring of alcohol-induced conformational transitions of ubiquitin upon exposure to increasing concentrations of methanol. A bottom-up analysis of deuterium labeled ubiquitin was used in this study to examine the local conformational transitions of ubiquitin upon exposure to solutions of varying concentrations of methanol. Analysis of ubiquitin and nine peptide fragments, produced from a ubiquitin-pepsin digest, were monitored through the use of a Varian 500-LCMS ion trap. The bottom-up approach to hydrogen/deuterium exchange mass spectrometry isolated most deuterium exchange to the $\beta$-strands of ubiquitin, suggesting the methanol-induced transitions of ubiquitin were highly characterized by the unfolding of the native-state $\beta$-sheets. 


\section{ACKNOWLEDGEMENTS}

I would like to express my sincere gratitude to San José State University and the entire California State University system for enabling me to pursue scientific research in both academia and the private sector. I would also like to thank the Department of Chemistry at San José State University for the opportunity to write and present a master's thesis. To my committee, Dr. Daryl Eggers, Dr. Lionel Cheruzel, and Dr. Brandon White, I am extremely grateful for your assistance, suggestions, and most importantly the time you have donated to helping me complete my thesis. An extra special thanks to Varian, Inc., for loaning a Varian 500-LCMS and complete use of their entire wet laboratory and all of its contents for the pursuit of my thesis. To my research advisor Dr. Daryl Eggers, thank you for your acquisition of ubiquitin and pepsin and most importantly organizing the completion of my thesis from across the globe.

To the most important people in my life, my family and friends, thank you all for your love and support. To Gloria, Clarissa, Ava and Stella, thank you for your unwavering devotion and being one of my main sources of motivation. To my primo Adrian, thank you for being an enduring source of determination. And to my primo Nick, thank you for your encouragement in pursuing further study in chemistry and in life. 


\section{TABLE OF CONTENTS}

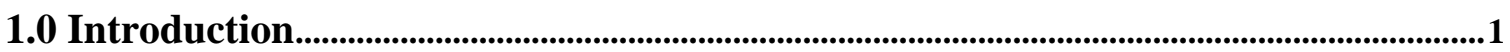

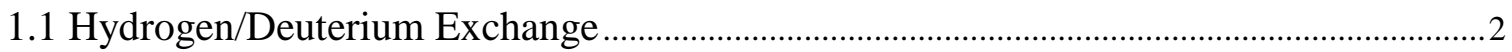

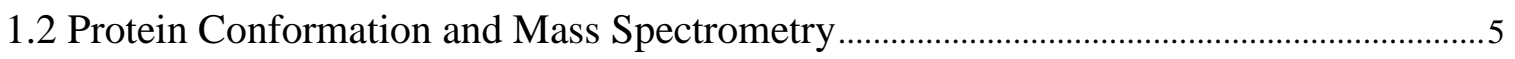

1.3 Bottom-Up Approach for Hydrogen/Deuterium Exchange Analysis .................................

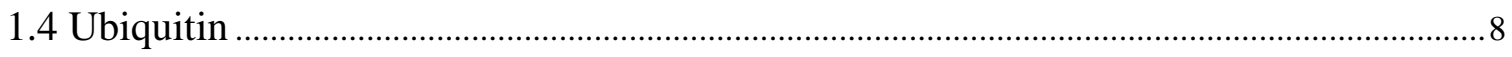

1.6 Bottom-up Hydrogen/Deuterium Exchange Analysis of Ubiquitin....................................12

2.0 Experimental Methods....................................................................................................................................14

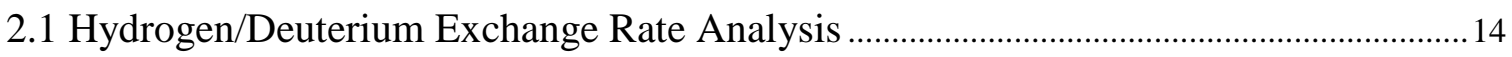

2.2 Reverse Phase Chromatography for HiRes Spectral Analysis ...........................................15

2.3 Bottom-up Hydrogen/Deuterium Exchange for HiRes Spectral analysis .........................19

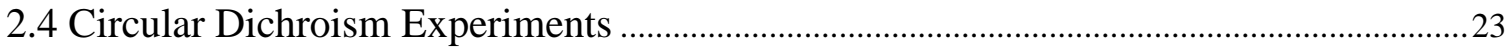

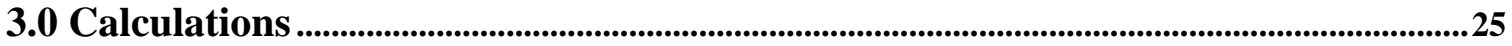

3.1 Calculations for a Single Point $\mathrm{m} / \mathrm{z}$ Reference for the Exchange Rate Determination

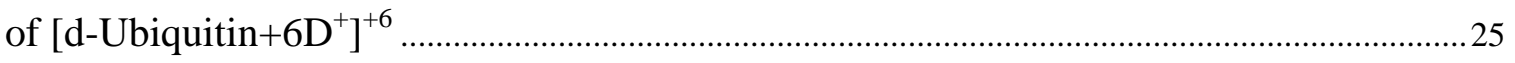

3.2 Identification of Peptide Fragments from the Peptic Digestion of Ubiquitin .................27

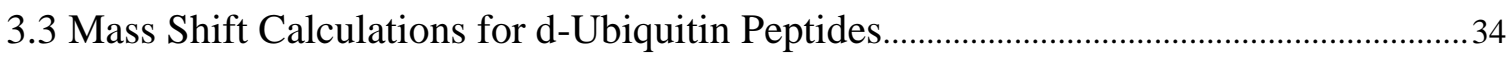

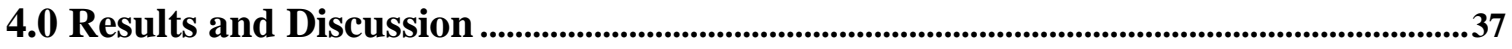


4.1 Circular Dichroism.

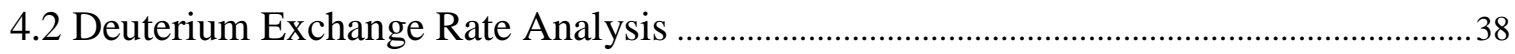

4.3 High Resolution Scan of d-Ubiquitin Peptide Fragments .................................................. 41

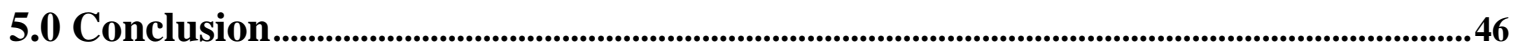

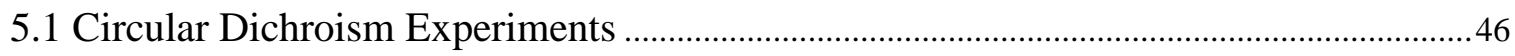

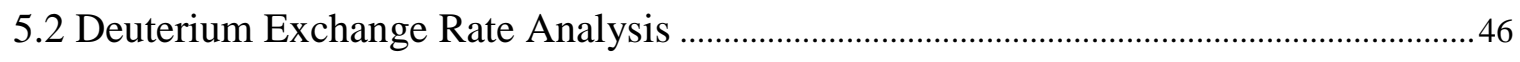

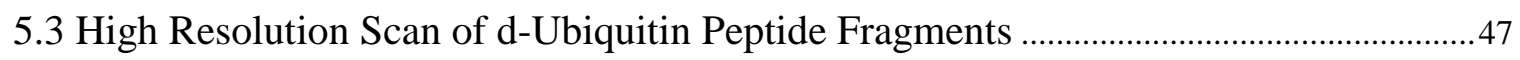

5.4 Bottom-up Hydrogen/Deuterium Exchange Analysis of Ubiquitin.................................50

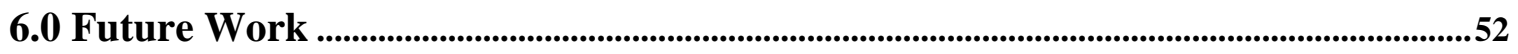

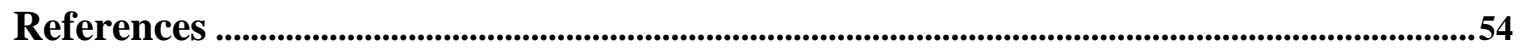




\section{LIST OF FIGURES}

Figure 1. Illustration of Ubiquitin

Figure 2. The Ubiquitin Sequence .10

Figure 3. General transitions of ubiquitin in solutions of increasing concentrations of methanol.

Figure 4. HPLC Parameters for the Elution of Ubiquitin Peptides

Figure 5. HPLC Column Covered in Artificial Ice

Figure 6. Solvents A and B Immersed in Ice Bath

Figure 7. HPLC Lines and Pumpheads Covered with Artificial Ice.

Figure 8. Complete LCMS System for d-Ubiquitin Peptic Digest .................................18

Figure 9. HiRes Spectral Analysis of Five Ubiquitin Peptides.

Figure 10. Preliminary Mass Analysis for the Determination of HiRes "Focal" m/z

Setpoints.

Figure 11. HiRes Analysis of Ubiquitin Peptide, AGKQLEDGRTLSD.

Figure 12. Illustration of Single Point $\mathrm{m} / \mathrm{z}$ Calculation .26

Figure 13. Single Point $\mathrm{m} / \mathrm{z}$ Calculation

Figure 14. The Chromatographically Separated m/z Spectra of Ubiquitin Peptic 
Digest .

Figure 15. Spreadsheet for Peptide Identification.

Figure 16. The Five Ubiquitin Peptides Selected for Bottom-up Deuterium Exchange .32

Figure 17. The Five Peptides Chromatographically Separated in a Gradient Elution.....33

Figure 18. HiRes Scan of Peptide HLVLRLRGG in 50\% $\mathrm{MeOH}$ .35

Figure 18b. List of Ions and Associated Intensities for the Average m/z Spectra of HLVLRLRGG .36

Figure 19. CD Spectra for Ubiquitin at $20 \mu \mathrm{M}$ in Various Concentrations of Methanol in

$\mathrm{D}_{2} \mathrm{O}$

Figure 20. ESI Mass Spectra of Ubiquitin at pH 2.7 in Various Concentrations of Methanol .39

Figure 21. Mass Assignments of [d-ubiquitin] ${ }^{+6}$ upon Exposure to Various Concentrations of $\mathrm{MeOH} / \mathrm{D}_{2} \mathrm{O}$. .40

Figure 22. Mass Shifts for Two Charge States of the Five Preselected Ubiquitin

Peptides

Figure 23. The Average Mass Shift Between Two Observed Charge States for Each of the Five Preselected Peptides. .43 
Figure 24. The Mass Shift Values Based on the Average Mass Shift of the Two Observed Charge States for Each of the Five Preselected Peptides ..................................44

Figure 25. Diagram for the Representation of Ubiquitin Native State Structure and the

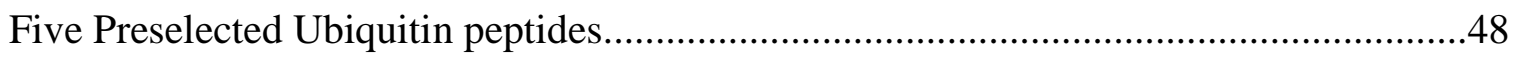




\subsection{Introduction}

Protein-focused applications in mass spectrometry have become an indispensable tool for the identification and quantification of proteins since the discovery of electrospray ionization (ESI) allowed for the electrical charging of full protein structures. Researchers have long studied the three-dimensional structure of proteins as a means of understanding the specificity and functionality of specific enzymatic reactions, but only until recently have scientists begun to study protein conformation through changes in protein mass. Mass spectrometry provides a method for observing global transitions in protein conformation as well as identifying local regions on a protein that are of increased flexibility and dynamic activity. Studies focused on the mechanics of protein folding and structure have become increasingly important in the search for cures to specific human biological disorders, a number of which have been directly linked to the misfolding of specific proteins; ${ }^{1}$ for example, some cases of Alzheimer's Disease have been directly attributed to the misfolding of protein HypF-N. ${ }^{2}$ These misfolded proteins have been shown to have a higher propensity for aggregation and set the foundation for the formation of destructive amyloid fibrils that interfere in the neurological pathways of the human brain.

The complexities in studying protein conformation are derived from the interwoven relationship amongst a multitude of inherent forces originating from the protein's immediate environment and a combination of intra-molecular forces from the protein's amino acid sequence. A protein's functionality is entirely reliant on its structure and thus becomes indirectly tied to the culmination of inherent forces responsible for producing a 
stable protein structure; making the study of protein conformations extremely difficult, as external molecules, such as water and metallic ions, along with other external influences, such as $\mathrm{pH}$, temperature, molecular crowding and external fields (magnetic, electrical) all have the potential for dramatically altering the conformation of a protein. ${ }^{3}$

\subsection{Hydrogen/Deuterium Exchange}

Hydrogen/deuterium exchange (HX) has become an important technique for the study of protein conformational transitions. By introducing a substantial source of deuterium to the external environment of a protein, typically by substituting $\mathrm{H}_{2} \mathrm{O}$ with $\mathrm{D}_{2} \mathrm{O}$ and through the addition of $[\mathrm{D}]^{+}, \mathrm{HX}$ can take advantage of the secondary structure's propensity to exchange hydrogen at neutral $\mathrm{pH}$. Although the rates of hydrogen exchange differ between labile hydrogens in the amino acid sequence, exchange is often complete within a few minutes for small peptides in which all labile hydrogen is accessible. This is often the case for the more slowly exchanging backbone amide hydrogen when compared to the very rapid rates of exchange for labile hydrogen on the amino acid side chains. ${ }^{4}$

Hydrogen exchange rates for a peptide can be divided into three groups based on the hydrogen position within a peptide: hydrogens covalently bonded to carbon with extremely slow rates of exchange, side chain hydrogens with very rapid exchange rates,

and hydrogens bonded to the backbone amide which exchange at well documented rates. ${ }^{4}$ The rate of exchange for hydrogens on the amide backbone has been shown to deviate by only small increments resulting from minor influences presented by the amino acid side 
chain. These influences have been shown to rely overwhelmingly on the steric hindrance of additional amino acid side chains rather than any dipole moment influences presented by various side chains. ${ }^{5}$ HX utilizes these known rates of exchange for the amide hydrogen as the focal point for determination of deuterium uptake on a protein.

At neutral $\mathrm{pH}$, hydrogen exchange on the amide backbone has been shown to occur rapidly (at rates of $\left.k_{\text {Hexchange }}=10^{1} \mathrm{~s}^{-1}-10^{3} \mathrm{~s}^{-1}\right)^{5}$ following a base catalysis mechanism with $\mathrm{H}_{2} \mathrm{O}$. The rapid rates of exchange yield an extremely short half-life, in the order of milliseconds, making all deuterium exchange at neutral $\mathrm{pH}$ highly susceptible to rapid rates of back exchange. ${ }^{6}$

The average rates of peptide amide hydrogen exchange as a function of $\mathrm{pH}$ showing a minimum in the rate as the mechanism for exchange is altered from a base-catalysis to an acid-catalysis method. ${ }^{7}$ The minimum rate of exchange for the amide hydrogen resides at a $\mathrm{pH}$ of 2.7 with a half-life of about 10 minutes under normal laboratory conditions, further cooling of the substrate to $0^{\circ} \mathrm{C}$ substantially quenches the exchange of amide hydrogen to a half-life of about $2 h{ }^{8}$ The kinetic isotope effects from the substitution of hydrogen to deuterium has been shown to have minimal impact on the quenching state of deuterium amide exchange. ${ }^{9}$ By locking deuterium into place at the amide backbone, the quenching state allows ample time for an experiment to monitor deuterium uptake on the amide backbone. 
Deuterium uptake at the protein backbone alters measurable characteristics at the points of exchange, most notably the increase in mass and the alteration of magnetic spin from the substitution of hydrogen to deuterium. The presence of high concentrations of deuterium in a HX experiment, compared to those of hydrogen, ensure an extremely high probability that all exchange at the amide backbone occurs with the chemically reactive analog, deuterium.

The dependency between the rate of deuterium substitution and the position of the amide backbone in the three-dimensional structure of a protein is the fundamental basis for probing protein conformations and fluctuations within the tertiary structure. HX experiments ${ }^{7}$ have shown the rate of deuterium substitution to have a profound relationship to the amide's location within the tertiary structure of a protein, illustrating a higher propensity for amides located on the outer-surface of a protein to undergo higher rates of deuterium substitution when compared to amides buried within a protein. These observations have yielded a deuterium-amide exchange rate that is dependent on two main factors: (1) the degree to which the amide backbone is protected from the solvent, and (2) the extent to which it is involved in internal hydrogen bonds to surrounding residues in the secondary and tertiary structure. ${ }^{7}$

Higher rates of deuterium exchange for amides are not necessarily exclusive to locations on the outer surface of a protein but can result from areas of high flexibility within the protein structure. ${ }^{10}$ These regions may increase the probability of deuterium exchange by increasing the exposure of solvent-shielded amides to the external 
environment or by weakening internal hydrogen bonds that could have otherwise bounded the amide and restrained it from any exchange. These areas on a protein with increased mobility and dynamics are of particular interest when studying important sites of activity in biological enzymes. ${ }^{11}$ Mass shift observations derived from the mass difference in hydrogen bound proteins to those obtained in a hydrogen/deuterium exchange experiment are measured through the use of a mass spectrometer and offer a quantitative way of monitoring the degree of deuterium uptake.

\subsection{Protein Conformation and Mass Spectrometry}

Polar amino acids in the secondary structure of a protein facilitate most of the ionization of proteins for introduction into a mass spectrometer. Ionization techniques, such as Electrospray Ionization (ESI), ionize proteins through the implementation of high voltages and temperatures to the protein solution as it passes through a nebulizer. Positive polarities applied to proteins in solution oxidize the basic amino acids, lysine, arginine,

and histidine, through the addition of a proton, resulting in a positive charge on the amino acid side chain and constituting one part of the total charge on a protein.

Ionization techniques like ESI and matrix assisted laser desorption ionization (MALDI) often use the protein solution as an intermediary in the production of a protein ion. Methods for positive ionization in ESI are often run at low $\mathrm{pH}$ to provide a substantial source of $[\mathrm{H}]^{+}$to protonate the basic amino acids. This dependency of $[\mathrm{H}]^{+}$in solution has been used to explain shifts in charge state population for different protein conformations. 
Circular dichroism analysis ${ }^{12.13}$ involving $\beta$-lactoglobulin, cytochrome $c$, and ubiquitin have shown shifts to structures with greater helical content as the concentration of methanol in solution is increased. Mass spectrometry experiments ${ }^{4,14,15}$ on these same proteins reported shifts to higher charge states as the proteins were exposed to increasing concentrations of methanol. Positive ESI of these proteins in solutions, thought to promote a native state structure, were observed to ionize at relatively low charge states, while solutions that promote high helical structure are shown to ionize at higher charge states. $^{15}$

In much the same way as hydrogen deuterium exchange is heavily reliant on the exposure of the amide backbone to the external environment for the uptake of deuterium, so too is the oxidation of the amino acid side chains dependent to the external environment. Access of $\left[\mathrm{H}^{+}\right]$for oxidation of the basic side chains from solution is a direct consequence of the position of the amino acid in the tertiary structure of the protein. This dependency has led to observations illustrating a general tendency for compacted protein structures with decreased surface area to reside at lower charge states; a spatial conformation that inherently reduces accessibility of any basic amino acids to oxidation from the electric potential of the ESI source. ${ }^{16}$ While an unfolded protein with greater surface area was viewed with a tendency to populate higher charge states, the result of greater exposure of the polar amino acids to the external solvent and additional stability gained from the dispersion of charges within the protein, limiting repulsion from multiple charge states that may have otherwise been unattainable in a more compacted protein. Experiments by Babu et al. ${ }^{15}$ reported major shifts to higher charge state for ubiquitin as 
the concentration of methanol in solution was increased, suggesting that methanol will interfere with the native state structure of ubiquitin and cause it to undergo changes to its tertiary structure.

\subsection{Bottom-Up Approach for Hydrogen/Deuterium Exchange Analysis}

Proteolytic cleavage of proteins has been used to generate a "fingerprint" identification method for qualitative protein analysis. Typically, a protease with a high degree of specificity is used to cleave proteins at particular points within the protein sequence based on a high preference for a specific peptide sequence. The chromatographic separation and subsequent mass spectral analyses of these generated peptides are compared to calculated peptide masses or mass spectral library analysis to yield a piece-wise analysis of a full protein sequence.

The digestive protease enzyme, pepsin, present in the stomach of many organisms is a very strong digestive enzyme used to cleave many different types of proteins at many different peptide sites. The very low specificity of pepsin makes it a poor choice for fingerprinting the peptide sequence. But because its inherent function is that of a digestive enzyme, it is fully active at $\mathrm{pH} 1.9$, making it an ideal enzyme for proteolysis at the quenching state conditions in a HX experiment.

The deuterium-labeled peptide fragments resulting from digestion with pepsin can be chromatographically separated for individual mass spectral analysis. Mass shifts observed in the peptide fragment mass spectra are used as a means of quantifying the deuterium uptake to more specific regions on the protein. The analysis of protein 
fragment mass shifts in a hydrogen/deuterium exchange experiment offers a localized view of deuterium uptake on a protein and clues to local modifications within the protein structure that are otherwise hidden in an analysis of a fully intact protein. ${ }^{17}$

\subsection{Ubiquitin}

Ubiquitin is a small protein consisting of 76 amino acids and a molecular mass of about $8.5 \mathrm{kDa}$; it is present in all eukaryotes with a structure and function well studied in many scientific journals. It has been shown to have a fundamental role in human physiology, serving as a molecular label for a myriad of biological functions, including cell-cycle regulation, DNA repair, cell growth and immune function. ${ }^{18}$ The protein has been observed in all eukaryotes with a highly conserved amino acid sequence between many different organisms, differing by only $4 \%$ when comparing human ubiquitin to that of yeast. The native state structure of ubiquitin has been observed through x-ray diffraction experiments with a single 3.5 turn $\alpha$-helix and four $\beta$-sheets with a few interwoven random turns (Fig. 1). ${ }^{19}$ 


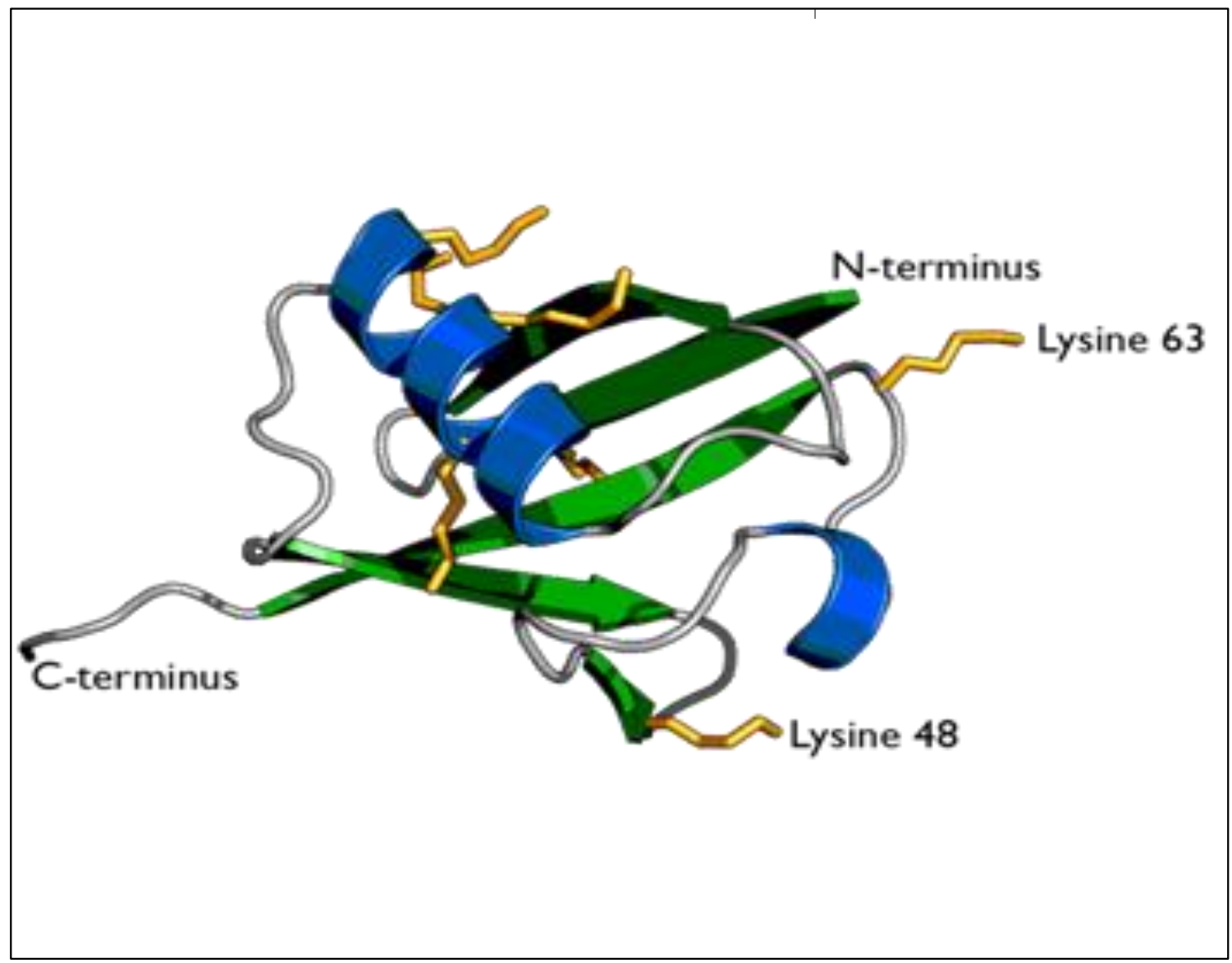

Fig. 1. Illustration of ubiquitin. Illustration of crystal structure of ubiquitin showing the tertiary structure of native state ubiquitin with helical structure in blue, beta sheet structure in green and six lysine residues. ${ }^{20}$

The ubiquitin amino acid sequence from bovine erythrocytes contains 144 labile hydrogens with 72 residing on the amide backbone and 72 on the side chains. The protein has 13 basic side chains suggesting 14 points of oxidation (including the ntermini) in positive electrospray ionization (Fig.2). 
Fig. 2. The ubiquitin sequence. The polar basic amino acids, lysine (K), arginine (R), and histidine $(\mathrm{H})$ are in red font.

\subsection{Conformational Analysis of Ubiquitin Using Hydrogen/Deuterium Exchange Mass} Spectrometry

Spectral studies ${ }^{13}$ using the $[\Theta]_{222}$ values of the CD spectra were able to deduce two distinct protein conformations apart from the native state of ubiquitin, in solutions of increasing concentrations of methanol. Ubiquitin was shown to increase helical structure over its native state by $26 \%$ in solutions of $35 \%$ methanol, reaching a highly helical denatured state at $90 \%$ methanol with a $62 \%$ increase in helical structure subsequently, having the same helicity in $90 \%$ methanol as a urea-induced denatured state. ${ }^{21}$

Mass spectral analysis ${ }^{15}$ of ubiquitin at low $\mathrm{pH}$ showed a progression to higher charge states as the concentration of methanol increased from 0 to $90 \%$. A custom laboratory quadrupole mass spectrometer was able to deduce two distinct stages of charge state progression, indicating a shift in the equilibrium of native and denatured states and the presence of large-scale conformational changes. The study showed native state ubiquitin ( $0 \%$ methanol) to produce a bimodal charge state distribution at $5^{+}$and $6^{+}$, retaining this distribution as the methanol concentration is increased to 25\%. At $30 \%$ methanol, ubiquitin was shown to ionize at higher charge states with a bell-shaped distribution around $10^{+}$, continuing this trend until the bimodal charge state distributions at $5^{+}$and $6^{+}$are significantly decreased at $90 \%$ methanol. 
Hydrogen deuterium exchange mass spectrometry experiments (HXMS) ${ }^{15,16,21,22}$ have been conducted on ubiquitin to provide greater resolution in monitoring the large scale conformational changes associated with the electrospray ionization mass spectrometry (ESIMS) full scan experiments on methanol-induced conformational changes to ubiquitin. The HXMS experiments on ubiquitin showed moderate uptake of deuterium as the concentration of methanol increased from 0 to $30 \%$, reaching a maximum rate of exchange at $\sim 50 \%$ methanol and steadily decreasing, as the concentration approaches $90 \%$, to rates near the native state structure.

The rate of exchange is indicative of a conformational transition in ubiquitin from its native state structure at $0 \%$ methanol to a slowly evolving intermediate state in concentrations of 10-30\% methanol. This slow increase in deuterium uptake on the protein is in agreement with the ESIMS full scan experiments which show a slow progression in charge state distribution up to $30 \%$ methanol before experiencing a more aggressive transition to $35 \%$, a point at which HXMS experiments were shown to reach a more rapid increase in the rate of exchange.

Further analysis of the deuterium exchange rate shows a maximum at $\sim 50 \%$ methanol followed by a slow decrease in exchange to $90 \%$ methanol; these findings were in accordance with the ESIMS full scan experiments which showed an almost complete transition from low to high charge states at $60 \%$ methanol. ${ }^{22}$ Further increases in methanol showed no significant changes to the charge state distribution while HD exchange experiments did show deuterium uptake to steadily decrease over this range 
suggesting that the protein conformation was still undergoing a dynamic transition as the concentration of methanol increased beyond $60 \%$. A point in which Babu et al. ${ }^{15}$ contributes a continuing transition in 60 to $90 \%$ methanol to a higher state of helicity and small changes in the overall cross section of the protein which is in agreement with the CD spectra, ESIMS full scan and HXMS experiments. Using these observations and those of $\beta$-lactoglobulin and cytochrome $c$, the transitions observed in ubiquitin as it is exposed to greater concentrations of methanol can be generalized to four transition states (Fig.3).

\begin{tabular}{|cccc|}
\hline $\begin{array}{c}\text { Native Protein } \\
\text { State }\end{array}$ & $\begin{array}{c}\text { Highly Unfolded } \\
\text { Intermediate State }\end{array}$ & Highly Denatured & Helical Denatured \\
$(\mathrm{N})$ & $\left(\mathrm{I}_{\mathrm{M}}\right)$ & $(\mathrm{H})$ & $\begin{array}{c}\text { State } \\
\left(\mathrm{H}_{\mathrm{c}}\right)\end{array}$ \\
0 to Low & $\begin{array}{c}\text { Moderatre } \\
\text { Conc. Alcohol }\end{array}$ & High & Very High \\
Conc. Alcohol & Conc. Alcohol & Conc. Alcohol \\
\hline
\end{tabular}

Fig. 3. General transitions of ubiquitin in solutions of increasing concentrations of methanol.

\subsection{Bottom-up Hydrogen/Deuterium Exchange Analysis of Ubiquitin}

This thesis relies on observations from past experiments that monitored the global methanol-induced transitions of ubiquitin as a direct consequence of methanol in solution; most notably experiments conducted by Babu et al. ${ }^{15}$ and Wright et al. ${ }^{21,22}$ are recreated using an alternative mass spectrometer and differences in calculating the mass shift in ubiquitin, serving as a means to test procedures employed in the bottom-up hydrogen\deuterium exchange mass spectrometry analysis of ubiquitin. 
Through the use of a bottom-up approach to hydrogen/deuterium exchange mass spectrometry, this thesis intends to study local methanol-induced transitions in ubiquitin as the concentration of methanol is increased from 0 to $90 \%$. The experiment uses methanol as a denaturant for inducing helical structure in ubiquitin. The thesis experiment aims to isolate local confirmations in a way that may be used to identify regions of high dynamicity in other proteins; the expectation is that these regions are of extreme importance in the study of protein functionality and could be precursor to studying pathways and possible causes of protein misfolding or the identification of protein active sites for the production of enzymatic inhibitors. 


\subsection{Experimental Methods}

Ubiquitin from bovine erythrocytes, U6253, pepsin from porcine gastric mucosca, P6887, $\mathrm{D}_{2} \mathrm{O}$ (99.990, atom \% D), $\mathrm{DCl}\left(35 \%\right.$ in $\mathrm{D}_{2} \mathrm{O}, 99.5$ atom \% D), $\mathrm{CH}_{3} \mathrm{COOD}$ (98 atom \% D), $\mathrm{CH}_{3} \mathrm{OH}$ (anhydrous, 99.8\%), ACN (anhydrous, 99.8\%), $\mathrm{HCl}$ (ACS reagent, $37 \%$ ) and formic acid ( $98 \%$, for mass spectroscopy) were all obtained from SigmaAldrich (St. Louis, MO.). All $\mathrm{H}_{2} \mathrm{O}$ was purified to $>18.0 \mathrm{M} \Omega$ through PURELAB ${ }^{\circledR}$ Option-R Water Purification System (Siemens Pittsburgh, PA).

Mass spectral analysis was conducted on a Varian 500-LCMS ion trap utilizing an electrospray ionization source with a needle potential of $5000 \mathrm{~V}$. All samples were injected at a flow rate of $10 \mu \mathrm{l} / \mathrm{min}$ with 35 psi nebulizing gas pressure. The drying gas temperature was set to $350^{\circ} \mathrm{C}$, voltages to the spray shield set to $600 \mathrm{~V}$, and the capillary set to $80 \mathrm{~V}$; the trap was filled with He damping gas at $0.8 \mathrm{ml} / \mathrm{min}^{22}$

Ubiquitin was diluted to $1000 \mu \mathrm{M} / \mathrm{H}_{2} \mathrm{O}$ and used as the base solution for all ubiquitin analysis. Deuterium exchange solutions of $\mathrm{D}_{2} \mathrm{O}$ with varying percentages $(0,10$, $25,50,75,90 \%)$ of methanol were adjusted with $\mathrm{DCl}$ to $\mathrm{pD} 2.0(\mathrm{pD}=\mathrm{pH}+0.4)^{26}$; ubiquitin base solution was dissolved in deuterium exchange solution to yield a final concentration of $10 \mu \mathrm{M} \mathrm{d}$-ubiquitin for full scan experiments and $100 \mu \mathrm{M}$ d-ubiquitin for the peptic digest analysis.

\subsection{Hydrogen/Deuterium Exchange Rate Analysis}

Mass spectral full scan experiments utilizing the enhanced scan mode at $5000 \mu \mathrm{s}^{-1}$ scan rate over a mass range of $50-2000 \mathrm{~m} / \mathrm{z}$ were used to monitor mass shifts in ubiquitin 
as a function of exchange time. The $10 \mu \mathrm{M}$ d-ubiquitin solution was manually injected using the Varian 500-LCMS syringe pump at flow rate of $10 \mu 1 / \mathrm{min}$ for $120 \mathrm{~min}$; injections were commenced rapidly after combining of ubiquitin base solution and deuterium exchange solutions. The experiment focused on the mass shift of [dubiquitin $\left.+6 \mathrm{D}^{+}\right]^{+6}$ ion over the span of $120 \mathrm{~min}$.

\subsection{Reverse Phase Chromatography for HiRes Spectral Analysis}

The d-ubiquitin peptide fragments were separated using two Varian 212-LC chromatography pumps in conjunction with a Varian Pursuit XRs-C18 column (250X2.0 $\mathrm{mm}, 3 \mu \mathrm{m}$ ) using a binary gradient elution (Fig. 4), utilizing $23.5 \mu \mathrm{M}$ formic acid/ $\mathrm{H}_{2} \mathrm{O}$ (Solvent A, $\mathrm{pH}=2.7 \pm 0.1$ ) and a second solution consisting of $100 \mathrm{~mL}$ of Solvent A and $100 \mathrm{~mL} \mathrm{ACN}+75.5 \mu \mathrm{L}$ formic acid (Solvent $\mathrm{B}, \mathrm{pH}=2.7 \pm 0.1$ ). Both mobile phase solutions were chilled to $0^{\circ} \mathrm{C}$ using an ice bath. 


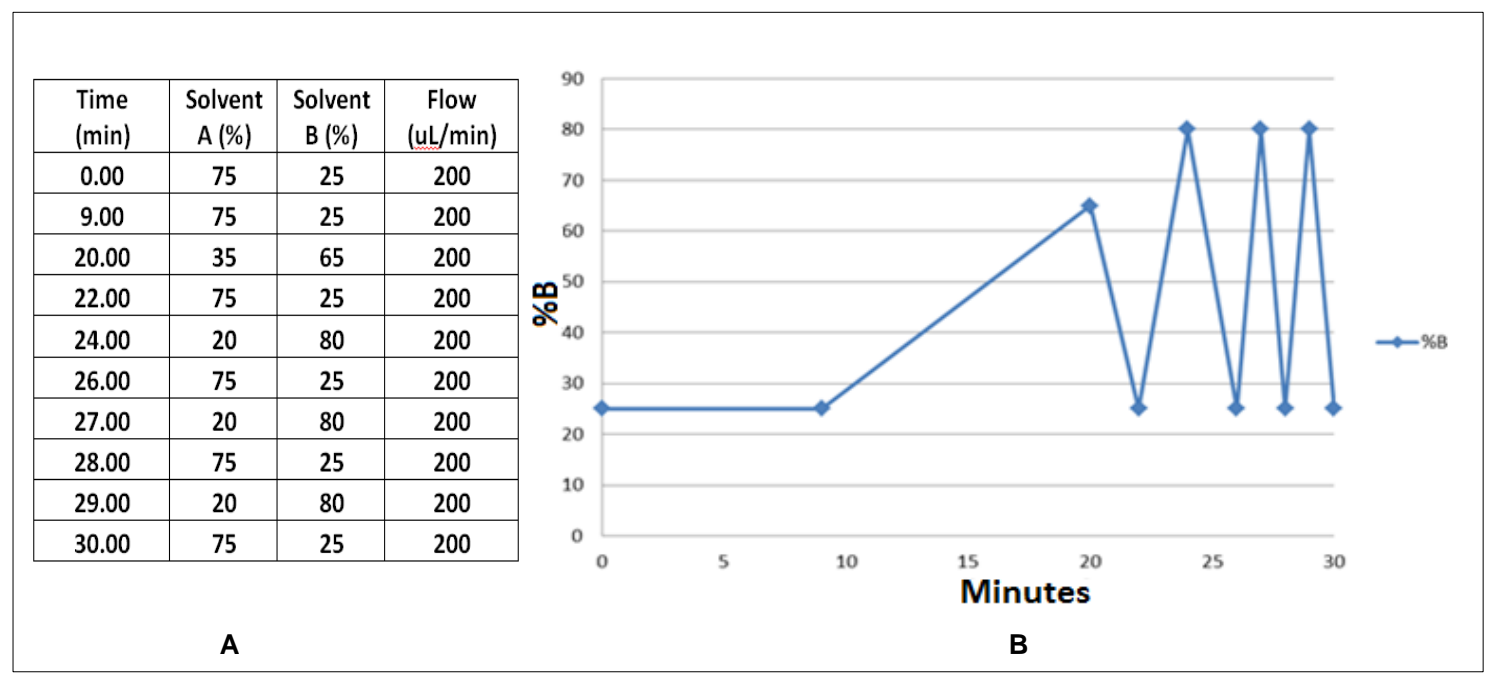

Fig. 4. A) Set HPLC parameters for the gradient elution of d-ubiquitin fragments.

B) Graphical representation of HPLC Solvent B composition following the injection of d-ubiquitin peptic digest at $0 \mathrm{~min}$.

Multiple components of the chromatographic setup, including the peak tubing used for solvent delivery, the LC pump heads, the $10 \mathrm{uL}$ sample loop with six port valve, the $200 \mathrm{uL}$ mixer, and the sample syringe, were chilled using frozen artificial ice packs filled with propylene glycol (Fig. 5-8). Particular interest in cooling was paid to the chromatographic column using large ice packs to promote uniform cooling throughout the column stationary phase. 


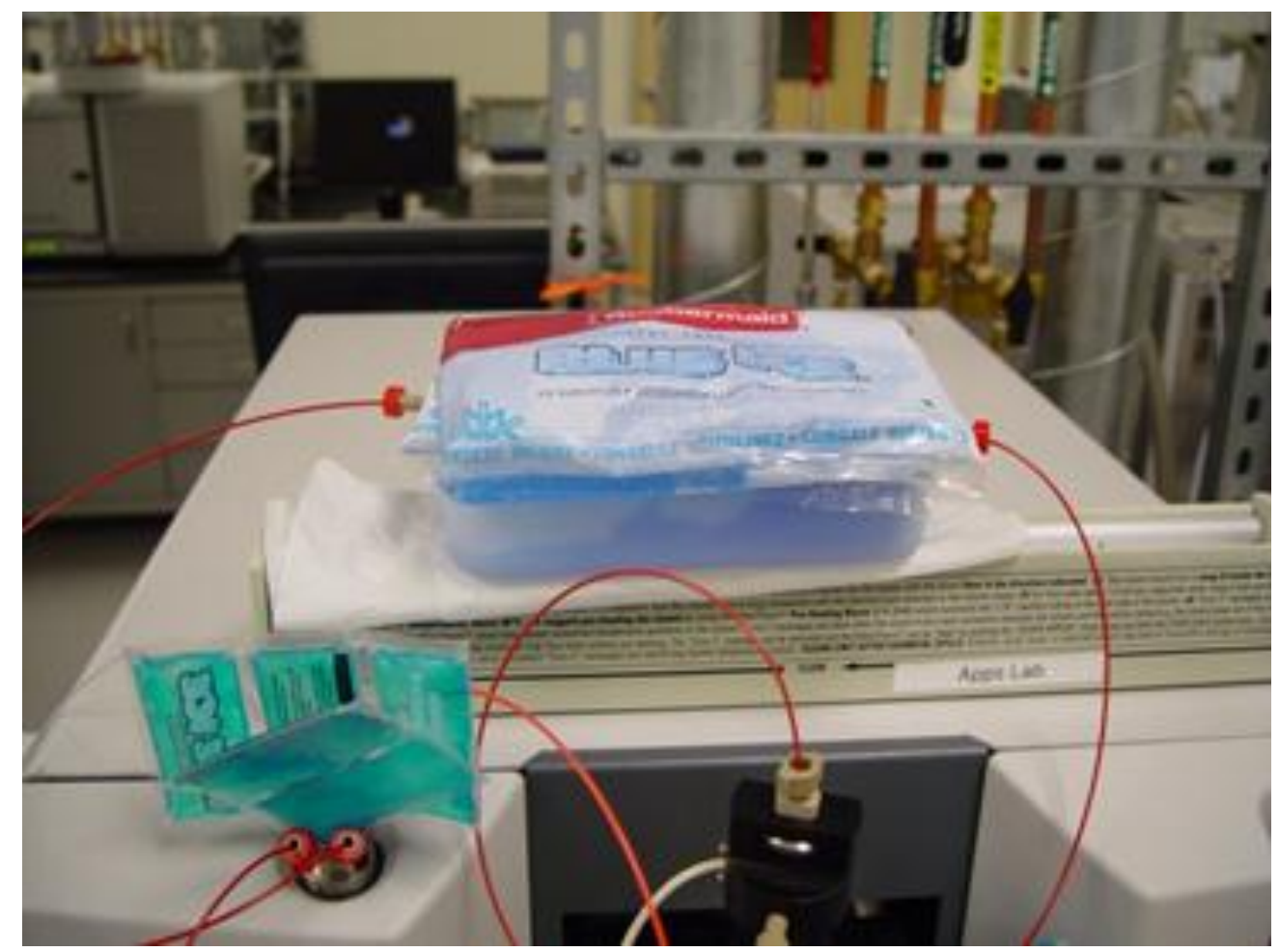

Fig. 5. HPLC column covered using frozen artificial ice packs filled with propylene glycol

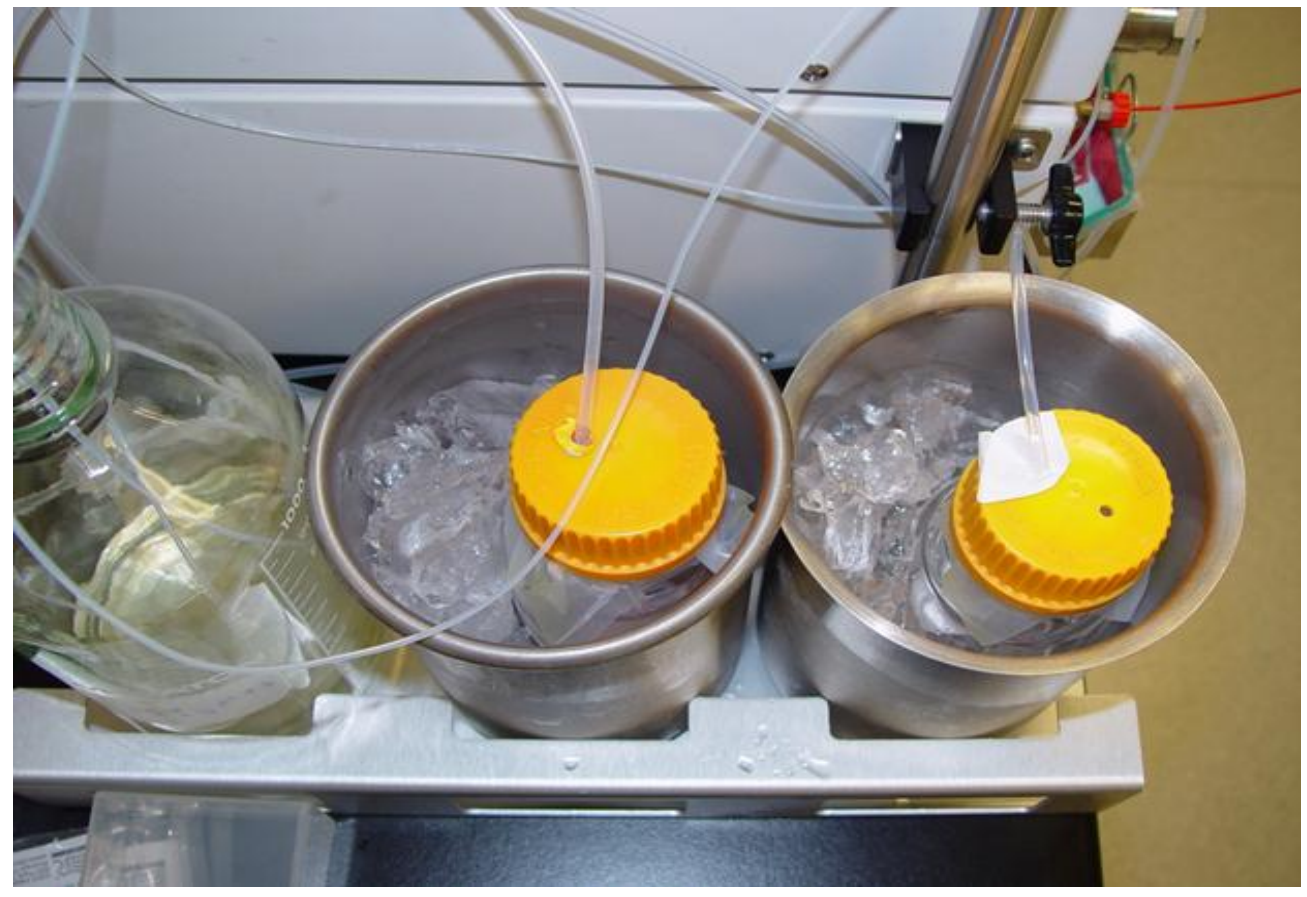

Fig. 6. Solvents A and B immersed in ice bath. 


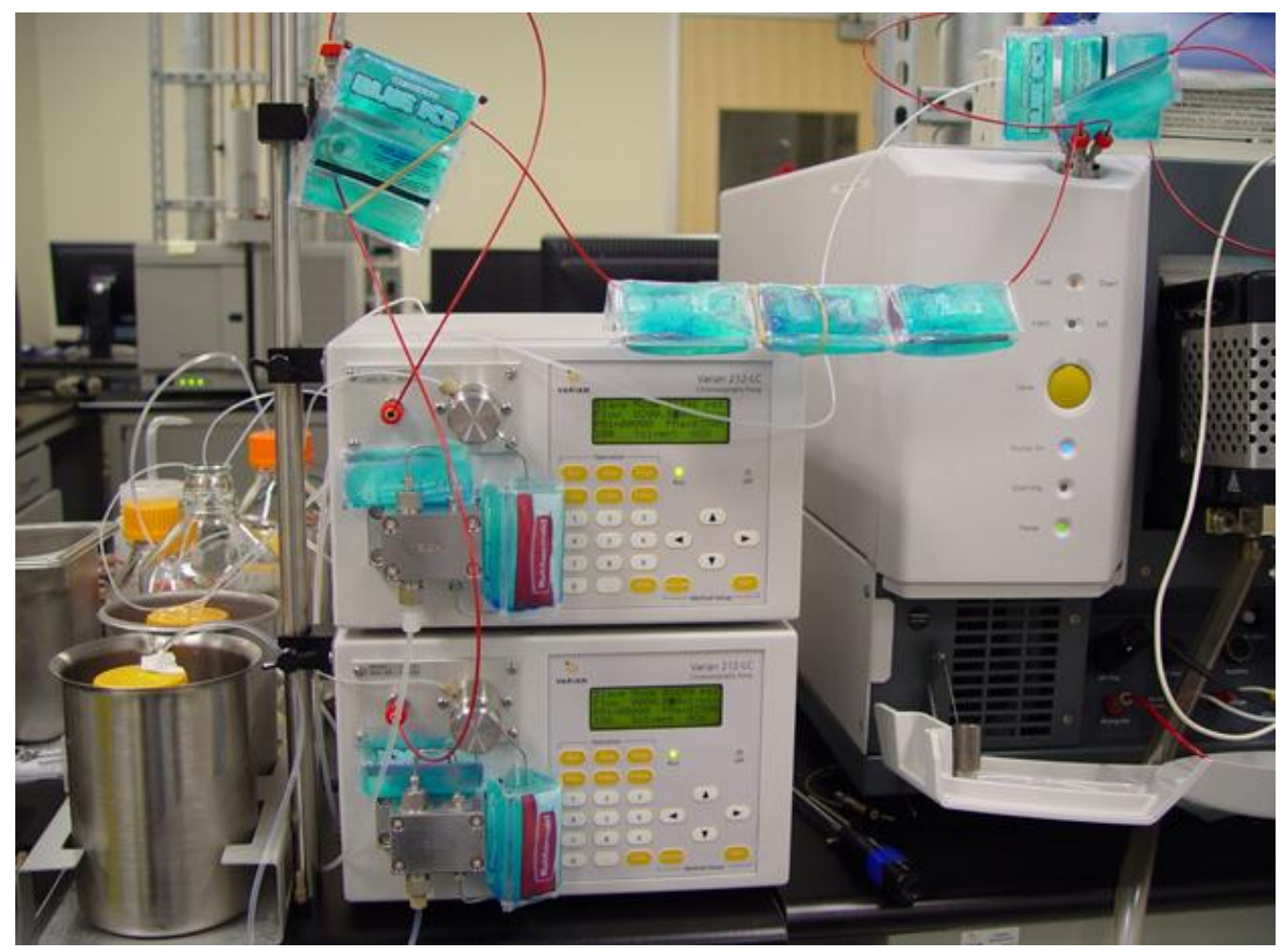

Fig. 7. HPLC lines and pumpheads wrapped in proplylene glycol ice packs.

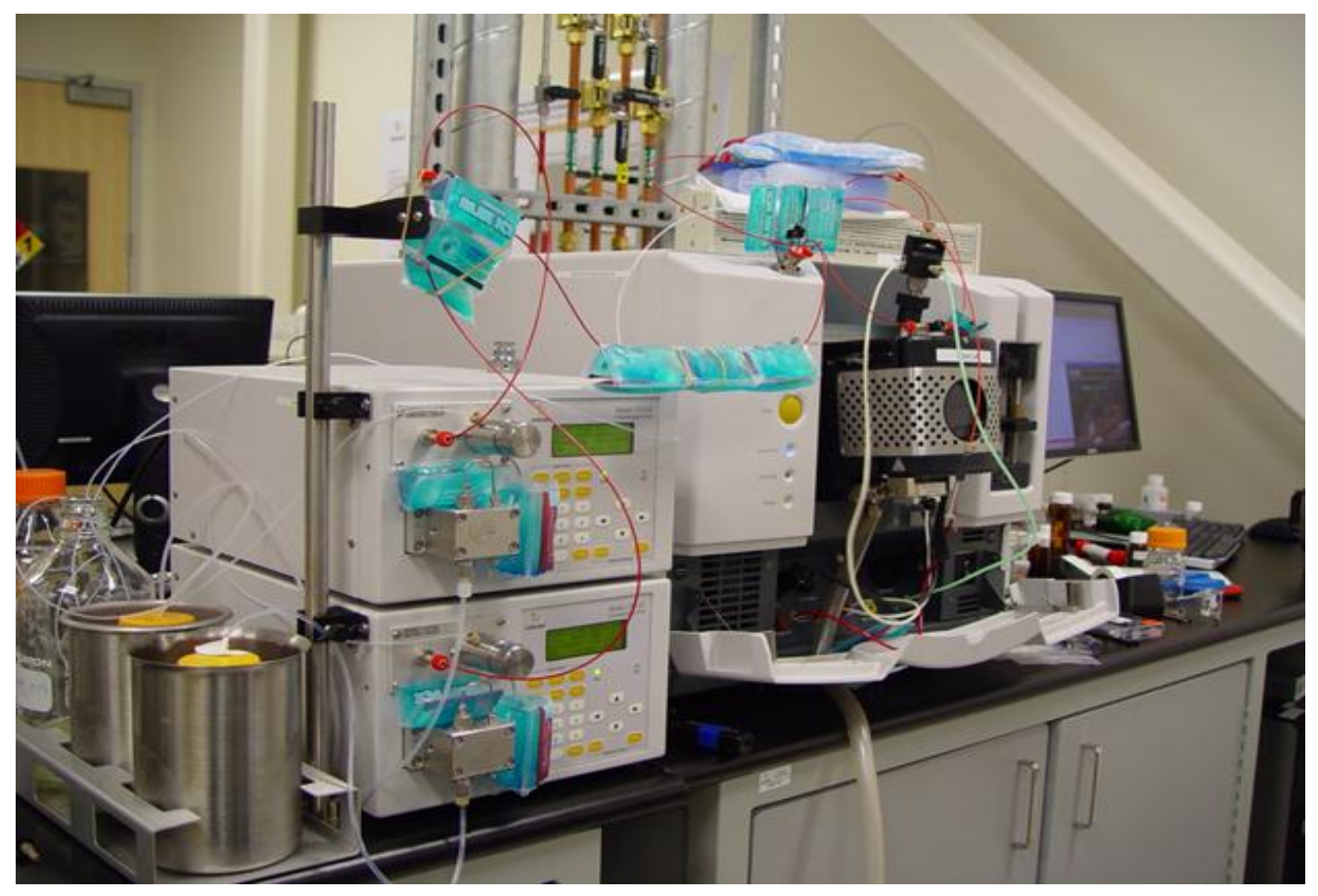

Fig. 8. Complete LCMS system in preparation for d-ubiquitin peptic digest. 


\subsection{Bottom-up Hydrogen/Deuterium Exchange for HiRes Spectral analysis}

Pepsin was diluted to $1000 \mu \mathrm{M} / \mathrm{H}_{2} \mathrm{O}$ and then activated upon dilution with $23.5 \mu \mathrm{M}$ formic acid $/ \mathrm{H}_{2} \mathrm{O}$ (Solvent $\left.\mathrm{A}, \mathrm{pH}=2.7 \pm 0.1\right)$ to yield a final concentration of $11 \mu \mathrm{M}$ pepsin digest solution. The activated pepsin solutions were chilled to $0^{\circ} \mathrm{C}$ using an ice bath in $900 \mathrm{uL}$ aliquots; $100 \mu \mathrm{L}$ of $100 \mu \mathrm{M}$ d-ubiquitin exchange solution was incubated at room temperature for $1 \mathrm{hr}$ prior to immersion in an ice bath for 3 min before the commencement of digestion in $900 \mathrm{uL}$ pepsin digest solutions. The digestion of ubiquitin yielded a 1:1 mixture of d-ubiquitin and pepsin to ensure a rapid rate of proteolytic cleavage. The digest was retained in the ice bath for $5 \mathrm{~min}$ to allow for adequate digestion. A rapid $10 \mu \mathrm{L}$ sample loop injection of d-ubiquitin digest sample was chromatographically separated using a Varian 212-LC pump.

Mass spectral analysis of d-ubiquitin peptide fragments required a high degree of mass spectral resolution to resolve the mass shifts associated with deuterium exchange in each peptide. In order to achieve the highest possible resolution a mass analysis of five selected peptides, representing $\sim 90 \%$ of the ubiquitin protein, was conducted under HiRes scan mode at a $250 \mu \mathrm{s}^{-1}$ scan rate over a scan window of $15 \mathrm{~m} / \mathrm{z}$, set to rapidly observe two present charge states in each peptide (Fig. 9).

The narrow $15 \mathrm{~m} / \mathrm{z}$ scan window associated with HiRes scan mode required predetermination of the degree of mass shift for each peptide to prohibit any mass shift of d-peptides outside the $\mathrm{m} / \mathrm{z}$ analysis window. A preliminary mass analysis utilized a 5000 $\mu \mathrm{s}^{-1}$ scan rate with a scan window of $+200 \mathrm{~m} / \mathrm{z}$ from the average mass of each peptide 
(Fig. 10). The scan window was set to rapidly observe the $\mathrm{m} / \mathrm{z}$ of two peptide charge states. The preliminary mass analysis for the determination of the HiRes focal $\mathrm{m} / \mathrm{z}$ was conducted for all five selected peptides in all concentrations of denaturant.

The HiRes scan windows for the mass shift analysis of the five peptides were preset into individual timed segments, centered on the elution time of the individual peptides with the scan window centered on the "focal" $\mathrm{m} / \mathrm{z}$ derived from the preliminary mass analysis of d-ubiquitin fragments in the various concentrations of methanol (Fig. 11). 


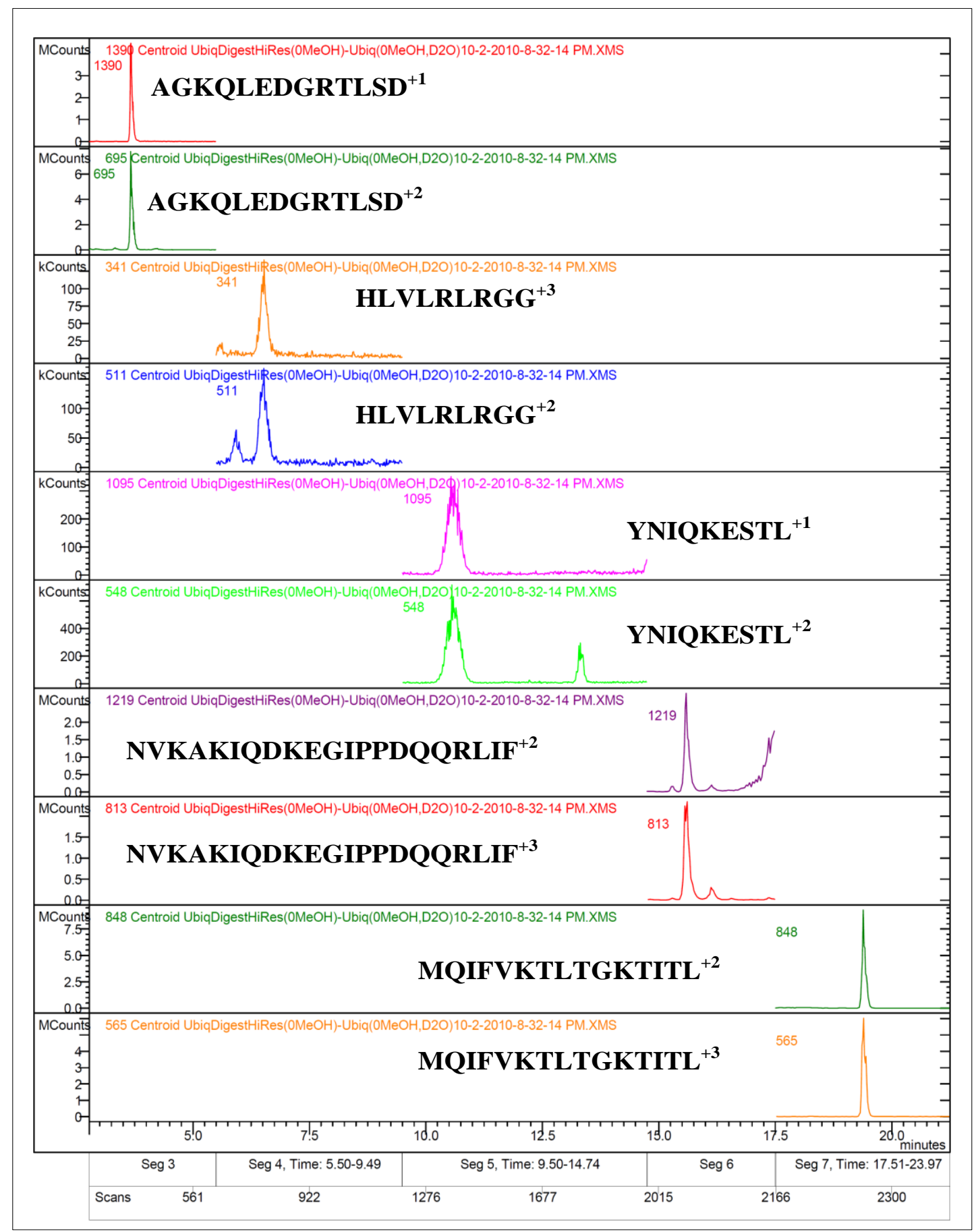

Fig. 9. HiRes analysis of five ubiquitin peptides were separated into five chronological segments utilizing a scan rate of $250 \mathrm{usec}^{-1}$ in scan window of $15 \mathrm{~m} / \mathrm{z}$. The focal $\mathrm{m} / \mathrm{z}$ derived from a preliminary mass analysis can be seen next to each peak. 


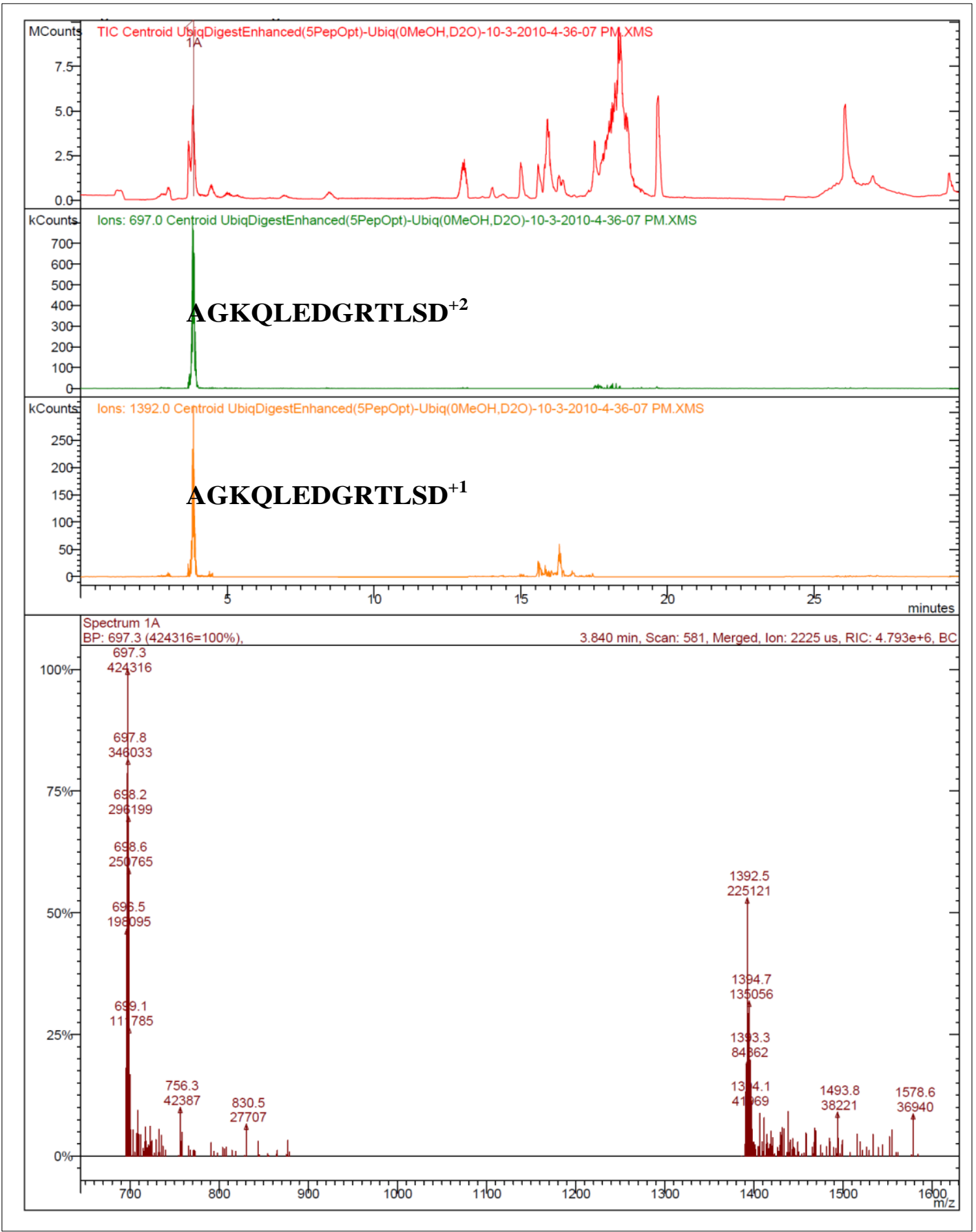

Fig. 10. Preliminary mass analysis for the determination of the HiRes "focal" $\mathrm{m} / \mathrm{z}$ setpoints. Mass analysis on the selected ubiquitin peptide AGKQLEDGRTLSD in 0\% $\mathrm{MeOH}$, utilizing a $5000 \mu \mathrm{sec}^{-1}$ scan rate with a scan window of $+200 \mathrm{~m} / \mathrm{z}$ from the average peptide mass. TIC in red, TIC- $697.0 \mathrm{~m} / \mathrm{z}$ filter in green, TIC-1392.0 m/z filter in yellow. 


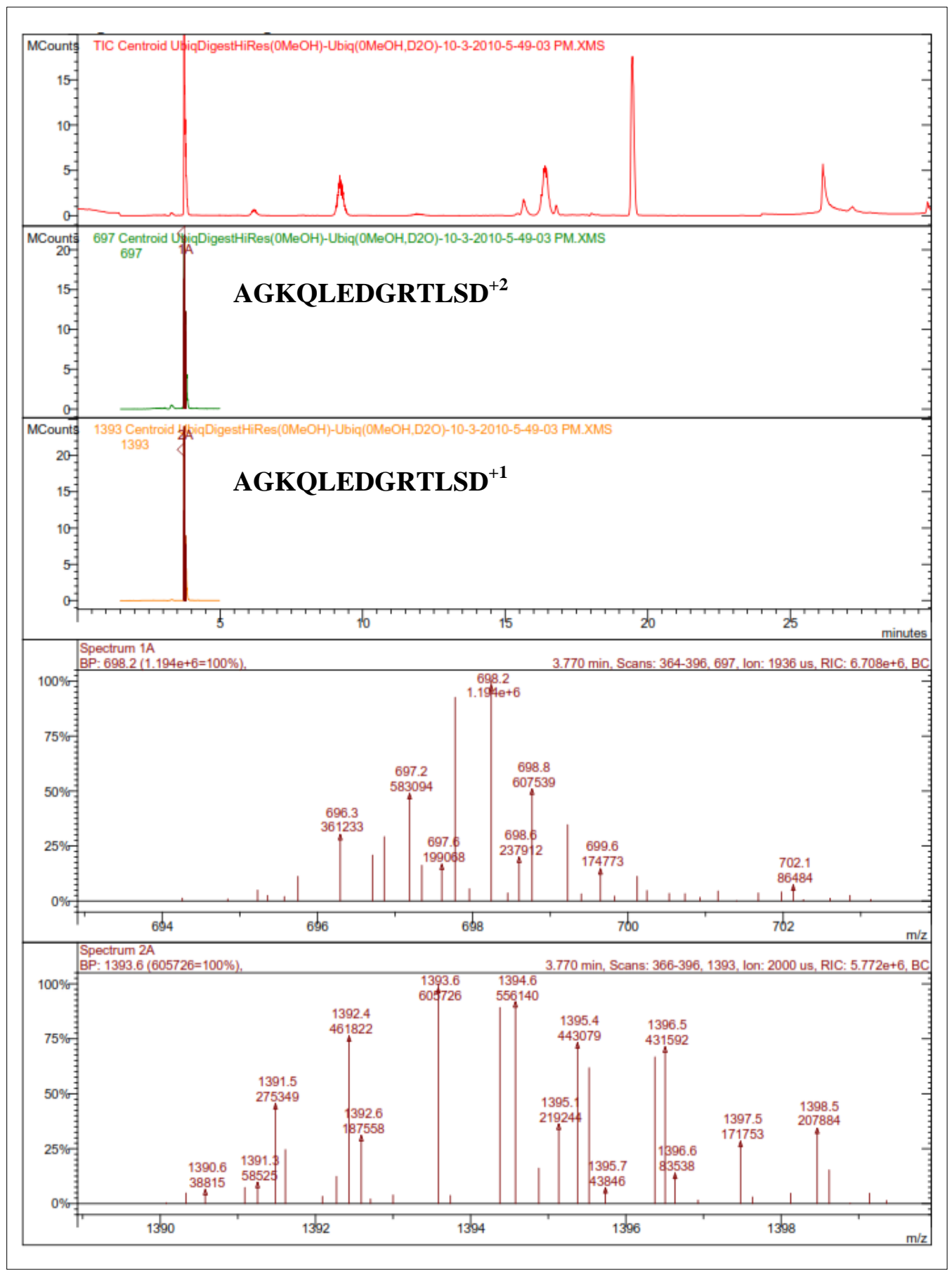

Fig. 11. HiRes analysis of ubiquitin peptide, AGKQLEDGRTLSD. Utilizing a scan rate of $250 \mathrm{usec}^{-1}$ in scan window of $15 \mathrm{~m} / \mathrm{z}$. The focal $\mathrm{m} / \mathrm{z}$ derived from a preliminary mass analysis at $1397 \mathrm{~m} / \mathrm{z}$ for $\mathrm{z}=+1$ and 697 for $\mathrm{z}=+2$. 


\subsection{Circular Dichroism Experiments}

Methanol-induced conformational changes in ubiquitin protein were observed with an Aviv Model 215 circular dichroism spectrometer equipped with a Peltier-type thermoelectric cell holder; $600 \mu \mathrm{L}$ samples of $20 \mu \mathrm{M}$ ubiquitin in $\mathrm{D}_{2} \mathrm{O}$ with varying percentages of methanol $(0,10,25,50,75,90 \%)$ were placed in a $2 \mathrm{~mm}$ path quartz

cuvette. Spectra were recorded at $25.0^{\circ} \mathrm{C}$ in the far-UV region with scans between 190 to $260 \mathrm{~nm}$ with $1.00 \mathrm{~nm}$ wavelength steps and averaged over $1.00 \mathrm{sec}$. 


\subsection{Calculations}

3.1 Calculations for a Single Point $\mathrm{m} / \mathrm{z}$ Reference for the Exchange Rate Determination of $\left[\mathrm{d}-\text { Ubiquitin }+6 \mathrm{D}^{+}\right]^{+6}$

Ionization of ubiquitin produces a broad range of $\mathrm{m} / \mathrm{z}$ for each charge state due to the statistical distribution of isotopes within the amino acid sequence. The distribution of $\mathrm{m} / \mathrm{z}$ for a single ubiquitin ion varies with distinct local maxima for ions of a specific charge (Fig. 12a); difficulty arises when trying to compare mass differences of ubiquitin ion due to the ambiguity of a single $\mathrm{m} / \mathrm{z}$ reference point. The comparison of timedependent mass shifts for ubiquitin, as it undergoes hydrogen deuterium exchange, requires a process for identifying a point of reference (single $\mathrm{m} / \mathrm{z}$ ) within the statistical distribution of ubiquitin ion to successfully monitor mass shifts of ubiquitin as a function of time.

In the hydrogen deuterium exchange rate analysis of ubiquitin in increasing concentrations of methanol, a single $\mathrm{m} / \mathrm{z}$ was used to represent the full $\mathrm{m} / \mathrm{z}$ distribution of $\left[\mathrm{d} \text {-ubiquitin }+6 \mathrm{D}^{+}\right]^{+6}$ at a specific point in time. Specific criteria were defined for all calculations to narrow the $\mathrm{m} / \mathrm{z}$ distribution of ubiquitin by eliminating all $\mathrm{m} / \mathrm{z}$ peaks that did not meet a $60 \%$ threshold based on the intensity of the base $\mathrm{m} / \mathrm{z}$ peak (Fig. 12b). Furthermore, all $\mathrm{m} / \mathrm{z}$ peaks meeting the $60 \%$ threshold but existing at a range greater than $5 \mathrm{~m} / \mathrm{z}$ from the base peak were deemed secondary spectral peaks existing in alternate local maxima away from the base peak and were eliminated from contention in the single point $\mathrm{m} / \mathrm{z}$ calculation (Fig. 12c). 


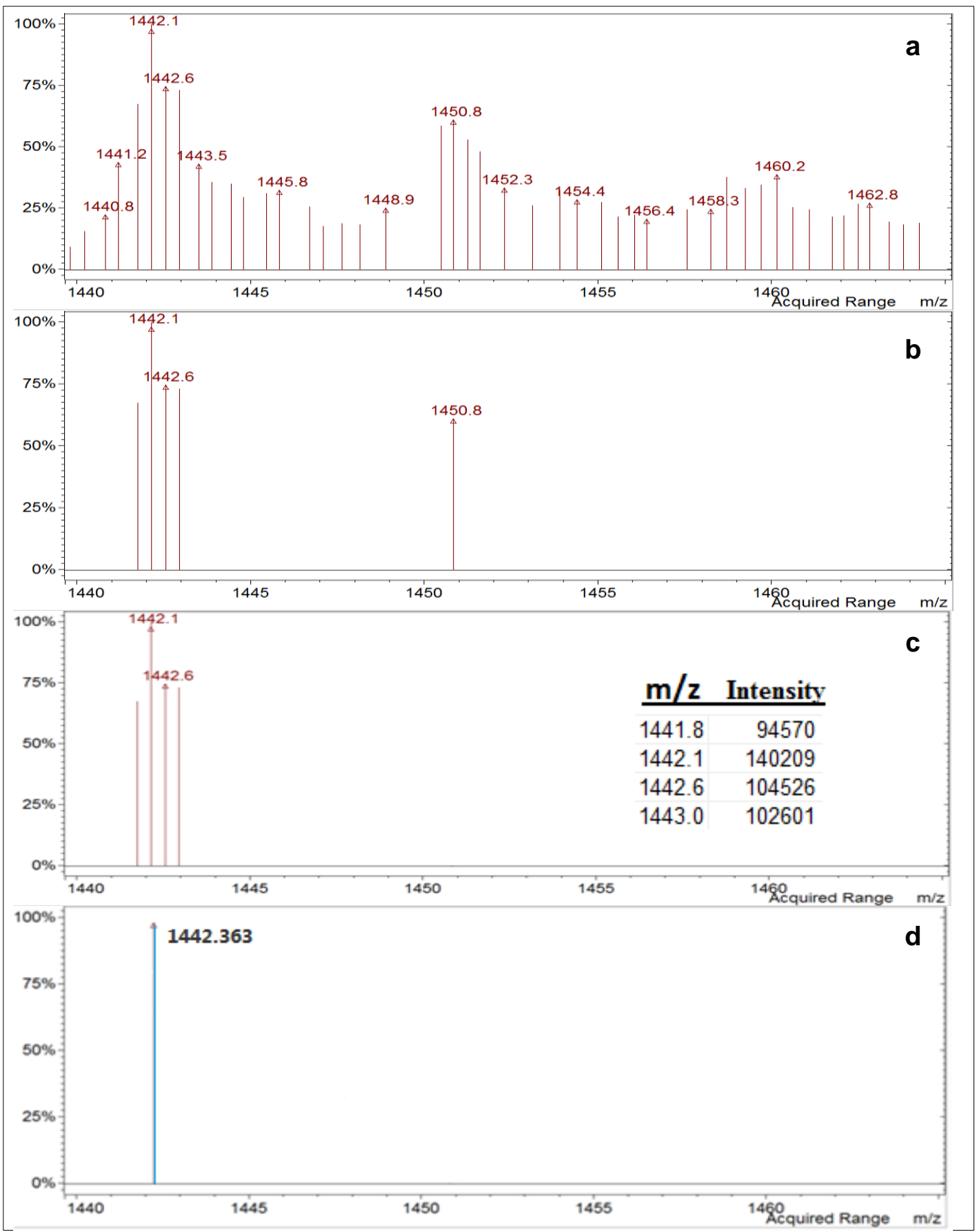

Fig. 12. Illustration of single point $\mathrm{m} / \mathrm{z}$ calculation. (a) Average $\mathrm{m} / \mathrm{z}$ distribution for [dubiquitin $^{+6}$ in $25 \% \mathrm{MeOH}$ at $50-51 \mathrm{~min}$ with a base peak of $1442.1 \mathrm{~m} / \mathrm{z}$. (b) $60 \%$ intensity threshold set for for the $\mathrm{m} / \mathrm{z}$ distribution of [d-ubiquitin] ${ }^{+6}$. (c) Elimination of peaks residing more than $5 \mathrm{~m} / \mathrm{z}$ from base peak with list of remaining ions and associated ion intensities. (d) Weighted average calculation applied to ions in Fig. 12c, resulting in single peak at $1442.363 \mathrm{~m} / \mathrm{z}$ used to represent entire m/z distribution in Fig.12a. 
A weighted average calculation (Fig. 13) was applied to the remaining $\mathrm{m} / \mathrm{z}$ peaks to produce a single $\mathrm{m} / \mathrm{z}$ point based on the $\mathrm{m} / \mathrm{z}$ and the associated intensity (Fig. 12d). The calculated single point $\mathrm{m} / \mathrm{z}$ was used to represent the entire $\mathrm{m} / \mathrm{z}$ distribution of [dubiquitin $\left.+6 \mathrm{D}^{+}\right]^{+6}$ at a specific chronological point within the exchange rate analysis.

$$
\text { Single } \mathrm{m} / \mathrm{z} \text { point }=\frac{\mathrm{m} / \mathrm{z}_{1} \cdot \text { Intensity }{ }_{1}+\mathrm{m} / \mathrm{z}_{2} \cdot \text { Intensity } \mathrm{y}_{2}+\ldots \mathrm{m} / \mathrm{z}_{\mathrm{x}} \cdot \text { Intensity }_{\mathrm{x}}}{\text { Intensity }{ }_{1}+\text { Intensity }_{2}+\ldots \text { Intensity }}
$$

Fig. 13. Single point $\mathrm{m} / \mathrm{z}$ calculation. Used to represent full mass spectra of [d-Ubiquitin $\left.+6 \mathrm{D}^{+}\right]^{+6}$ and to serve as point of reference for observing mass shifts brought on by the absorption of deuterium.

\subsection{Identification of Peptide Fragments from the Peptic Digestion of Ubiquitin}

The proteolyic enzyme, pepsin, exhibits a relatively high degree of non-specificity and optimum enzymatic activity at $\mathrm{pH} 1.8$ to 2.0 with some experiments reporting a slight affinity towards large bulky hydrophobic side chains. ${ }^{27}$ This lack of specificity most often results in a broad range of overlapping and over-digested protein fragments, making it an extremely difficult enzyme in a bottom-up approach to protein characterization. Despite this difficulty, pepsin remains one of the most commonly used proteases in hydrogen deuterium exchange experiments due to its robustness at $0^{\circ} \mathrm{C}$ and $\mathrm{pH} 2.7$, the optimal hydrogen/deuterium exchange quenching conditions. ${ }^{28}$ The digestion of proteins following a deuterium exchange enables a more localized analysis of deuterium uptake by offering a method for the mass comparison of peptide fragments. 
The experiment for the mass comparison of ubiquitin peptides following a hydrogen deuterium exchange first requires the successful identification and mapping of peptides to the fully intact ubiquitin protein. These peptides then serve as identifiers for gauging the varying degree of deuterium uptake in localized regions of the tertiary structure of a full protein.

Multiple studies ${ }^{27,29,30}$ have identified ubiquitin peptides resulting from peptic digestion through diverse experiments, most notably, Paloshoff et al., which reported six ubiquitin fragments in a study focused on the specificity of pepsin. The identification of ubiquitin peptide fragments used for the bottom-up hydrogen/deuterium exchange experiment, focused on a collection of identified ubiquitin fragments from other studies to form a list of 12 ubiquitin peptides known to occur as the result of pepsin proteolysis. These peptides allowed further determination of other possible peptides that may have occurred based on a process of elimination. The $\mathrm{m} / \mathrm{z}$ spectra of a chromatographically separated ubiquitin-pepsin digest was filtered for 12 known and 19 determined ubiquitin peptide masses which served as the basis for identifying ubiquitin fragments.

The digestion of ubiquitin yielded numerous peptide fragments as evident in the multitude of base peaks achieved in the chromatographic separation and subsequent qualitative mass analysis (Fig. 14). The process of identifying these peaks as a particular peptide of ubiquitin required matching the known and determined peptides, average isotopic mass to masses observed in the mass spectra of the chromatograms base peaks. 
The calculated $\mathrm{m} / \mathrm{z}$ of known peptides was placed in a spreadsheet with charges $(\mathrm{z})$ of +1 to +6 (Fig. 15).

Further credibility for a successful identification of a ubiquitin peptide was placed on base peaks which had matches to multiple charge states. Of the 31 known and determined peptides, 21 were shown to have $\mathrm{m} / \mathrm{z}$ matches to calculated mass with only 12 having matches to more than one charge. Peptides selected for further research under a hydrogen exchange experiment were selected from these 12 peptides having multiple matches to $\mathrm{m} / \mathrm{z}$. 


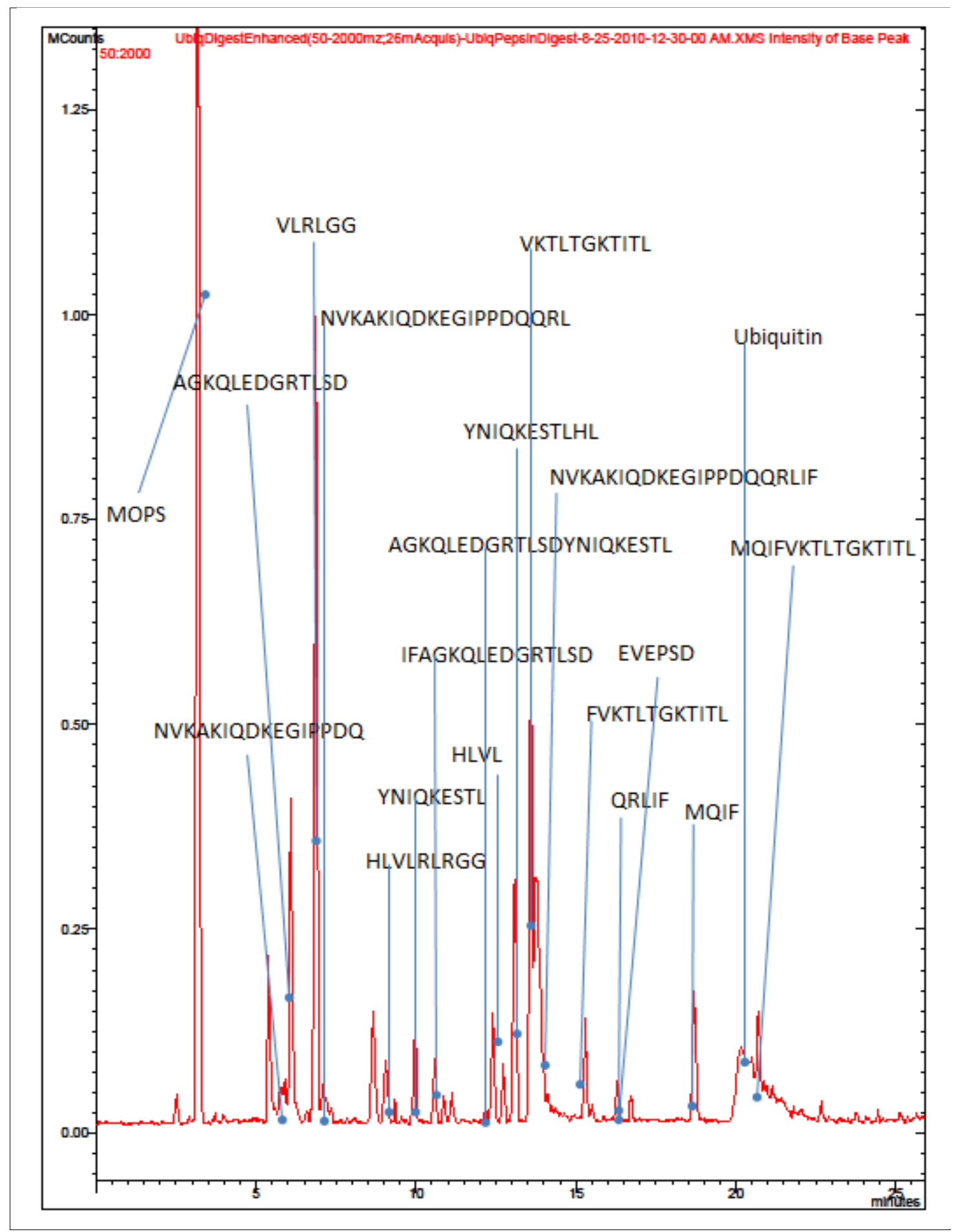

Fig. 14. The chromatographically separated $\mathrm{m} / \mathrm{z}$ spectra of ubquitin pepsin digest. Filtered to show the $\mathrm{m} / \mathrm{z}$ base peaks. Identification for various points of peptide elution was identified through filtering the spectra for known masses. 


\begin{tabular}{|c|c|c|c|c|c|c|c|c|c|}
\hline Seq. \# & Sequence & p.I & Avg M.W. & $M+1 H$ & $\mathrm{M}+2 \mathrm{H}$ & $\mathrm{M}+3 \mathrm{H}$ & $\mathrm{M}+4 \mathrm{H}$ & $\mathrm{M}+5 \mathrm{H}$ & $\mathrm{M}+6 \mathrm{H}$ \\
\hline $1-15$ & MQIFVKTLTGKTITL* & 10.00 & 1694.1 & 1695.1 & 848.1 & 565.7 & 424.5 & 339.8 & 283.4 \\
\hline $1-3$ & MQI & 5.28 & 390.5 & 391.5 & 196.3 & 131.2 & 98.6 & & \\
\hline $1-4$ & MQIF & 5.28 & 537.7 & 538.7 & 269.8 & 180.2 & 135.4 & & \\
\hline $4-15$ & FVKTLTGKTITL & 10.00 & 1321.6 & 1322.6 & 661.8 & 441.5 & 331.4 & 265.3 & 221.3 \\
\hline $5-13$ & VKTLTGKTI & 10.00 & 959.6 & 960.6 & 480.8 & 320.9 & 240.9 & & \\
\hline $5-15$ & VKTLTGKTITL & 10.00 & 1174.5 & 1175.5 & 588.2 & 392.5 & 294.6 & 235.9 & 196.7 \\
\hline $12-15$ & VKTLTGKTITLE & 8.56 & 1303.6 & 1304.6 & 652.8 & 435.5 & 326.9 & 261.7 & 218.3 \\
\hline $16-21$ & EVEPSD & 3.88 & 674.7 & 675.7 & 338.3 & 225.9 & 169.7 & 135.9 & 113.4 \\
\hline $16-23$ & EVEPSDTIE & 3.50 & 1018.0 & 1019.0 & 510.0 & 340.3 & 255.5 & 204.6 & 170.7 \\
\hline 21-23 & TIE & 4.00 & 361.4 & 362.4 & 181.7 & 121.5 & & & \\
\hline $25-45$ & NVKAKIQDKEGIPPDQQRLIF* & 8.50 & 2437.8 & 2438.8 & 1219.9 & 813.6 & 610.5 & 488.6 & 407.3 \\
\hline $44-45$ & IF & 5.52 & 278.4 & 279.4 & 140.2 & 93.8 & 70.6 & 56.7 & 47.4 \\
\hline $25-40$ & NVKAKIQDKEGIPPDQ & 6.12 & 1780.0 & 1781.0 & 891.0 & 594.3 & 446.0 & 357.0 & 297.7 \\
\hline $25-42$ & NVIKAKIQDKEGIPPDQQR & 8.50 & 2064.3 & 2065.3 & 1033.2 & 689.1 & 517.1 & 413.9 & 345.1 \\
\hline $25-45$ & NVKAKIQDKEGIPPDQQRL & 8.50 & 2177.5 & 2178.5 & 1089.7 & 726.8 & 545.4 & 436.5 & 363.9 \\
\hline 41-45 & QRLIF & 9.75 & 675.8 & 676.8 & 338.9 & 226.3 & 170.0 & 136.2 & 113.6 \\
\hline $50-59$ & LEDGRTLSDY & 4.03 & 1168.2 & 1169.2 & 585.1 & 390.4 & 293.1 & 234.6 & 195.7 \\
\hline $50-58$ & LEDGRTLSD & 4.27 & 1005.1 & 1006.1 & 503.5 & 336.0 & 252.3 & 202.0 & 168.5 \\
\hline 44-58 & IFAGKQLEDGRTLSD & 4.78 & 1649.0 & 1650.0 & 825.5 & 550.7 & 413.3 & 330.8 & 275.8 \\
\hline $52-56$ & DGRTL & 5.84 & 560.6 & 561.6 & 281.3 & 187.9 & 141.2 & 113.1 & 94.4 \\
\hline $46-52$ & AGKQLED & 4.67 & 759.8 & 760.8 & 380.9 & 254.3 & 191.0 & 153.0 & 127.6 \\
\hline $46-53$ & AGKQLEDG & 4.37 & 816.9 & 817.9 & 409.4 & 273.3 & 205.2 & 164.4 & 137.1 \\
\hline $46-58$ & AGKQLEDGRTLSD* & 4.78 & 1389.5 & 1390.5 & 695.7 & 464.2 & 348.4 & 278.9 & 232.6 \\
\hline $46-67$ & AGKQLEDGRTLSDYNIQKESTL & 4.78 & 2466.7 & 2467.7 & 1234.3 & 823.2 & 617.7 & 494.3 & 412.1 \\
\hline $59-66$ & YNIQKEST & 6.00 & 982.1 & 983.1 & 492.0 & 328.4 & 246.5 & 197.4 & 164.7 \\
\hline $59-67$ & YNIQKESTL* & 6.00 & 1095.2 & 1096.2 & 548.6 & 366.1 & 274.8 & 220.0 & 183.5 \\
\hline $59-69$ & YNIQKESTLHL & 6.75 & 1345.5 & 1346.5 & 673.8 & 449.5 & 337.4 & 270.1 & 225.3 \\
\hline $68-69$ & HL & 6.74 & 268.3 & 269.3 & 135.2 & 90.4 & 68.1 & 54.7 & 45.7 \\
\hline 68-71 & HLVL & 6.74 & 480.6 & 481.6 & 241.3 & 161.2 & 121.2 & 97.1 & 81.1 \\
\hline 68-76 & HLVLRLRGG* & 12.00 & 1020.3 & 1021.3 & 511.1 & 341.1 & & & \\
\hline $70-76$ & VLRLRGG & 12.00 & 770.0 & 771.0 & 386.0 & 257.7 & & & \\
\hline \multicolumn{10}{|c|}{ * Peptides used in HiRes analysis } \\
\hline & & \multicolumn{8}{|c|}{-Determining the Specifity of Pepsin for Proteolytic Digestion ${ }^{27}$} \\
\hline & & \multicolumn{8}{|c|}{-Mass Spectrometry Assisted Assignment of NMR Resonances in Labeled Proteins ${ }^{29}$} \\
\hline & & \multicolumn{8}{|c|}{-The Immunosuppressive Activity and Solution Structures of Ubiquitin Fragments. ${ }^{30}$} \\
\hline & & \multicolumn{8}{|c|}{-Determined Fragments } \\
\hline
\end{tabular}

Fig. 15. Spreadsheet for peptide identification. Showing the calculated $\mathrm{m} / \mathrm{z}$ of known and determined ubiquitin peptides. Basic amino acids on each peptide segment is in red. Observed $\mathrm{m} / \mathrm{z}$ in the mass spectra of chromatographically separated ubiquitin digest is filled in green. The $\mathrm{m} / \mathrm{z}$ corresponding to the highest charge possible for each peptide is in bold red. 
In order to create a more focused and efficient approach to studying the localization of deuterium exchange on ubiquitin, peptide fragments resulting from the peptic digest were further selected for continued study based on the intensity observed in the qualitative mass analysis and the degree of resolution achieved in the chromatographic separation. Based on these factors, five peptide fragments (Fig. 16) were selected for the continued study of deuterium exchange while still retaining the same coverage of ubiquitin offered by the 21 original peptides identified. The five peptides selected for the bottom-up approach to the study of hydrogen exchange on ubiquitin were able to account for close to $90 \%$ of the ubiquitin sequence, with 66 of the 76 ubiquitin amino acids identified in various peptide fragments. Optimization of the gradient for separation of the selected peptides was carried out to yield a timelier spaced elution (Fig. 17).

\begin{tabular}{|ccc|c|c|c|c|}
\hline 14 & & \\
\hline
\end{tabular}

Fig. 16. The five ubiquitin peptides selected for the bottom-up hydrogen/deuterium exchange. Including 66 of the 76 ubiquitin amino acids identified in five peptide segments accounting for close to $90 \%$ coverage of ubiquitin. 


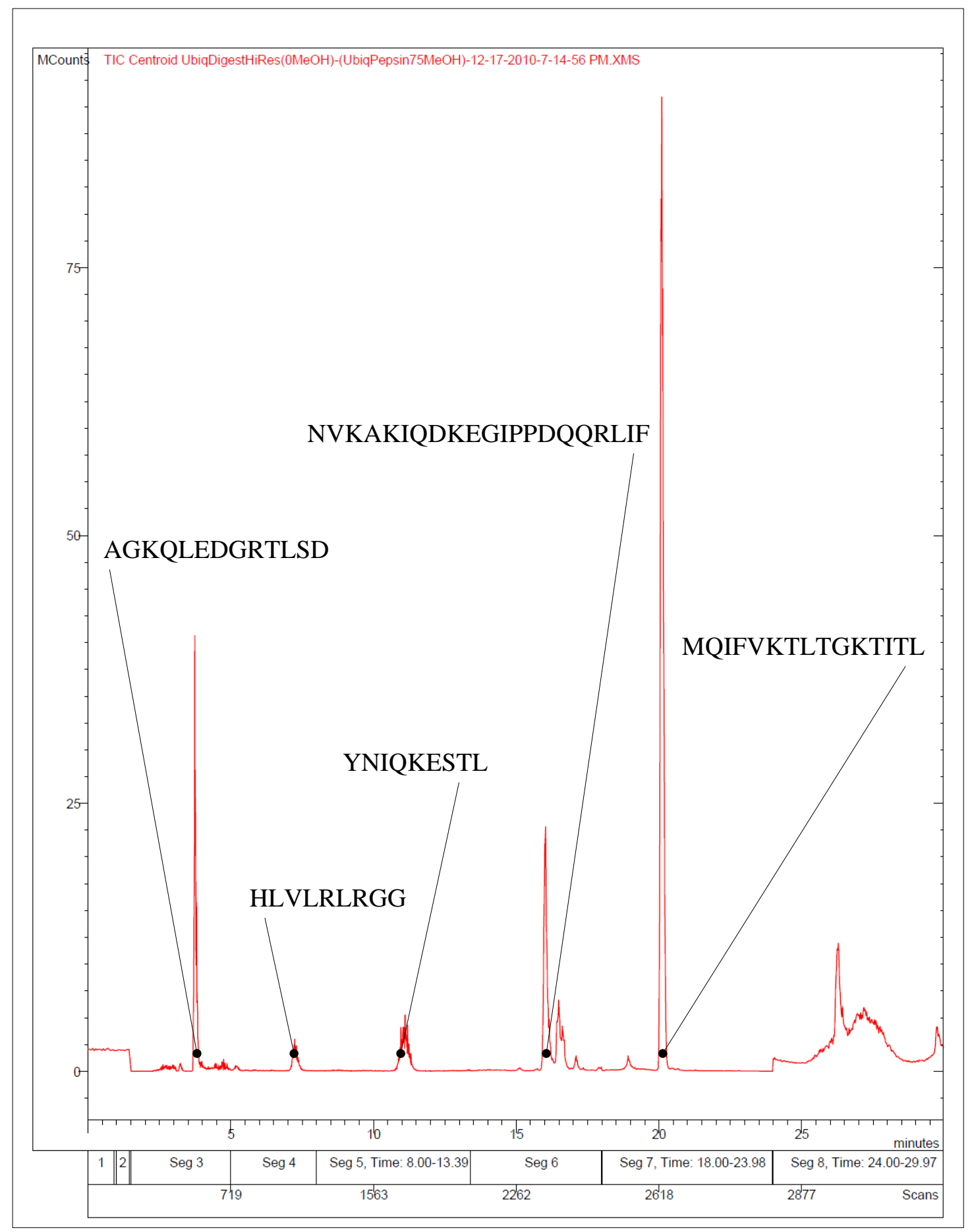

Fig. 17. The five peptides chromatographically separated in a gradient elution. The peptides were optimized to elute each peptide into a distinct Hi-Res mass spectral window. The mass window centered on masses set from preliminary full scan investigation of peptide mass shift. 


\subsection{Mass Shift Calculations for d-Ubiquitin Peptides}

Mass determination of d-ubiquitin peptides for the bottom-up analysis of deuterium uptake on ubiquitin focused on five selected peptides representing $\sim 90 \%$ of the ubiquitin sequence. The peptides were chromatographically optimized to elute at equidistant time intervals for mass analysis at $250 \mathrm{~s}^{-1}$ scan rates under segments of a predetermined mass window for each peptide. The determination of peptide mass shift in various concentrations of denaturant was calculated in similar fashion to the exchange rate analysis of ubiquitin, utilizing a weighted average for the single point $\mathrm{m} / \mathrm{z}$ calculation for the determination of d-peptide mass shift.

The HiRes mass analysis of each peptide was conducted in a $15 \mathrm{~m} / \mathrm{z}$ scan window for each peptide (Fig. 18); the mass spectra obtained from each mass segment was averaged over the entire mass peak to yield the average mass spectral plot, converted into list form to indicate the ion $\mathrm{m} / \mathrm{z}$ and the associated intensity (Fig. 18b). The ion mass assignments and their associated intensities obtained from the mass spectral analysis were populated into the same weighted average calculation used in the ubiquitin exchange analysis with a $50 \%$ abundance threshold relative to the base peak. 


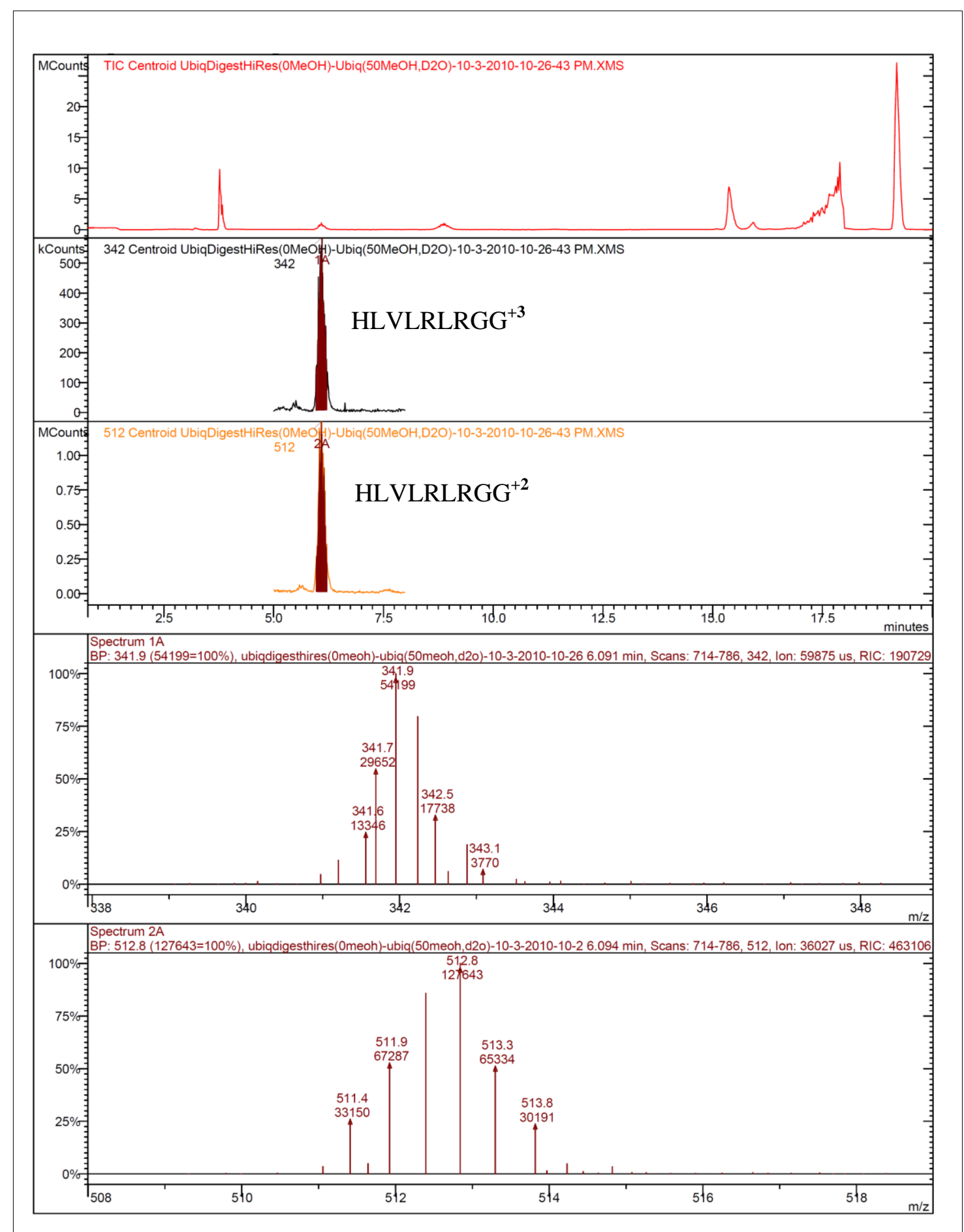

Fig. 18. HiRes scan of peptide HLVLRLRGG in 50\% MeOH. The total ion chromatogram filtered for 342 and $512 \mathrm{~m} / \mathrm{z}$ associated with the +2 and +3 charge states of peptide HLVLRLRGG. The average $\mathrm{m} / \mathrm{z}$ spectra from scan 714-786 (full peak average) obtained at $\mathrm{z}=2,3$. 


\begin{tabular}{|c|c|c|c|c|c|}
\hline ㅂ. Ion & $\begin{array}{ll}\uparrow & 1 \mathrm{~A} \text { Intensity }\end{array}$ & 原 $1 \mathrm{~A} \%$ Base & D) Ion & 原 $2 \mathrm{~A}$ Intensity & 的 $2 \mathrm{~A} \%$ Base \\
\hline 341.9 & 54199 & 100.0 & 512.8 & 127643 & 100. \\
\hline 342.2 & 43081 & 79.5 & 512.4 & 109456 & 85.8 \\
\hline 341.7 & 29652 & 54.7 & 511.9 & 67287 & 52.7 \\
\hline 342.5 & 17738 & 32.7 & 513.3 & 65334 & 51.2 \\
\hline 341.6 & 13346 & 24.6 & 511.4 & 33150 & 26. \\
\hline 342.9 & 10157 & 18.7 & 513.8 & 30191 & 23.7 \\
\hline 341.2 & 6118 & 11.3 & & & \\
\hline & & & & & \\
\hline
\end{tabular}

Fig. 18b. List of lons and associated intensities for the average $m / z$ spectra of HLVLRLRGG at $z=2,3$, used in the single point $\mathrm{m} / \mathrm{z}$ calculation for mass shift observations. 


\subsection{Results and Discussion}

\subsection{Circular Dichroism}

Circular dichroism experiments for the observation of methanol-induced conformational changes in ubiquitin depicted an increase in the helicity of the secondary structure as the concentration of methanol increased from 0 to $90 \%$ (Fig. 19). The spectra showed three regions of profound progression. Solutions containing 0, 10, and 25\% methanol were shown to yield structures with both $\beta$-sheet and $\alpha$-helix structure indicated by the relatively tame degree of ellipticity in the 190 to $200 \mathrm{~nm}$ wavelength region and again in the opposite elliptical node in the 200 to $230 \mathrm{~nm}$ region.

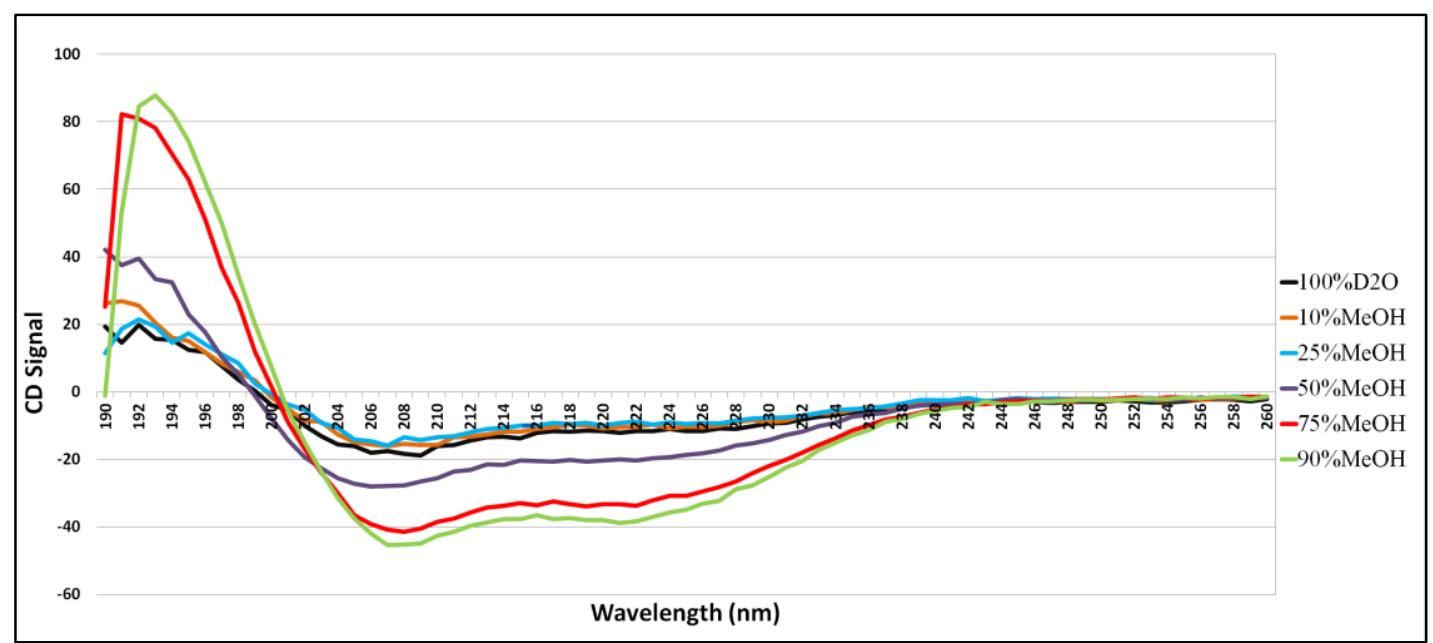

Fig. 19. CD spectra for ubiquitin at $20 \mu \mathrm{M}$ in various concentrations of methanol in $\mathrm{D}_{2} \mathrm{O}$.

Solutions of 75 and $90 \%$ methanol exhibited the most changes in ellipticity with relatively intense spectra profiles between 190 and $200 \mathrm{~nm}$ wavelengths and again in the 200 to $230 \mathrm{~nm}$ range, revealing the presence of high helicity in the protein. The absorption for ubiquitin in $90 \%$ methanol showed a slight increase in intensity consistent 
with greater helical structure than the ubiquitin conformation in $75 \%$ methanol solutions. The pattern of absorption for both solutions demonstrates a penchant towards a bimodal distribution in the 200-230 nm wavelength region, consistent with a structure of high helicity, becoming more pronounced as the solution increases to $90 \%$ methanol.

The absorption response for ubiquitin in solutions of 50\% methanol were observed to reside in a distinct region from the rest of the solutions with absorption rates that were close to mid-level, between the 25 and 75\% methanol solutions, indicative of an increase in helical structure compared to the native state ( $0 \%$ methanol) but less than the highly helical structure observed in the 75 and $90 \%$ solutions. Further examination of the absorption of ubiquitin at 50\% methanol shows the beginning of the bimodal pattern of response seen so prevalent in the 75 and $90 \%$ methanol solutions.

\subsection{Deuterium Exchange Rate Analysis}

The deuterium exchange rate analysis of ubiquitin in various concentrations of methanol focused on mass shifts to the +6 charge state of ubiquitin, [ubiquitin] ${ }^{+6}$ and were monitored in full scan mode $(100-2000 \mathrm{~m} / \mathrm{z})$ for 120 minutes. The full scan analysis of ubiquitin showed a clear transition to higher charge state distributions as the concentration of methanol increased from 10 to $90 \%$ an observation that was in close agreement with Babu et al. ${ }^{15}$ and Wright et al. ${ }^{21,22}$ (Fig. 20) 


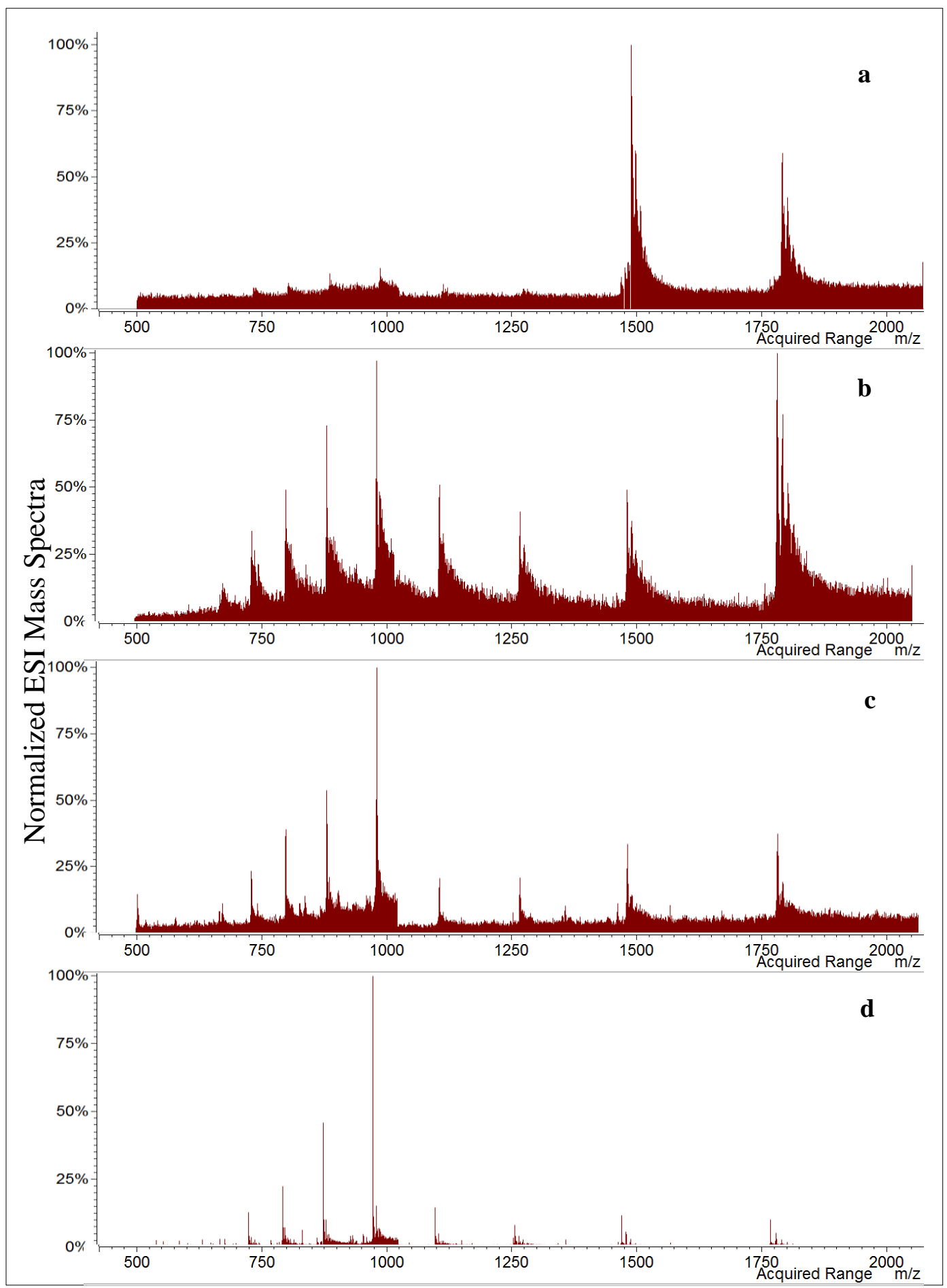

Fig. 20. ESI mass spectra of ubiquitin at $\mathrm{pH} 2.7$ in various concentrations of methanol, (a) $10 \%$, (b) $25 \%$, (c) 50\%, and (d) $90 \%$ methanol. The protein concentration was around $10 \mu \mathrm{M}$. 
Mass spectral analysis commenced immediately upon the introduction of ubiquitin to the various $\mathrm{MeOH} / \mathrm{D}_{2} \mathrm{O}$ solutions. The $\mathrm{m} / \mathrm{z}$ of [ubiquitin] ${ }^{+6}$ was plotted against time using the single point $\mathrm{m} / \mathrm{z}$ calculation to represent the overall $\mathrm{m} / \mathrm{z}$ of [d-ubiquitin] ${ }^{+6}$. Mass analysis of [d-ubiquitin $]^{+6}$ showed a rapid increase in mass upon injection of the analyte, followed by a gradual leveling off after about 60 minutes for each of the five methanol solutions (Fig. 21). The rates and degree of mass shift were clearly affected by the concentration of $\mathrm{MeOH}$ in solution, indicating a direct influence on the rate of deuterium exchange.

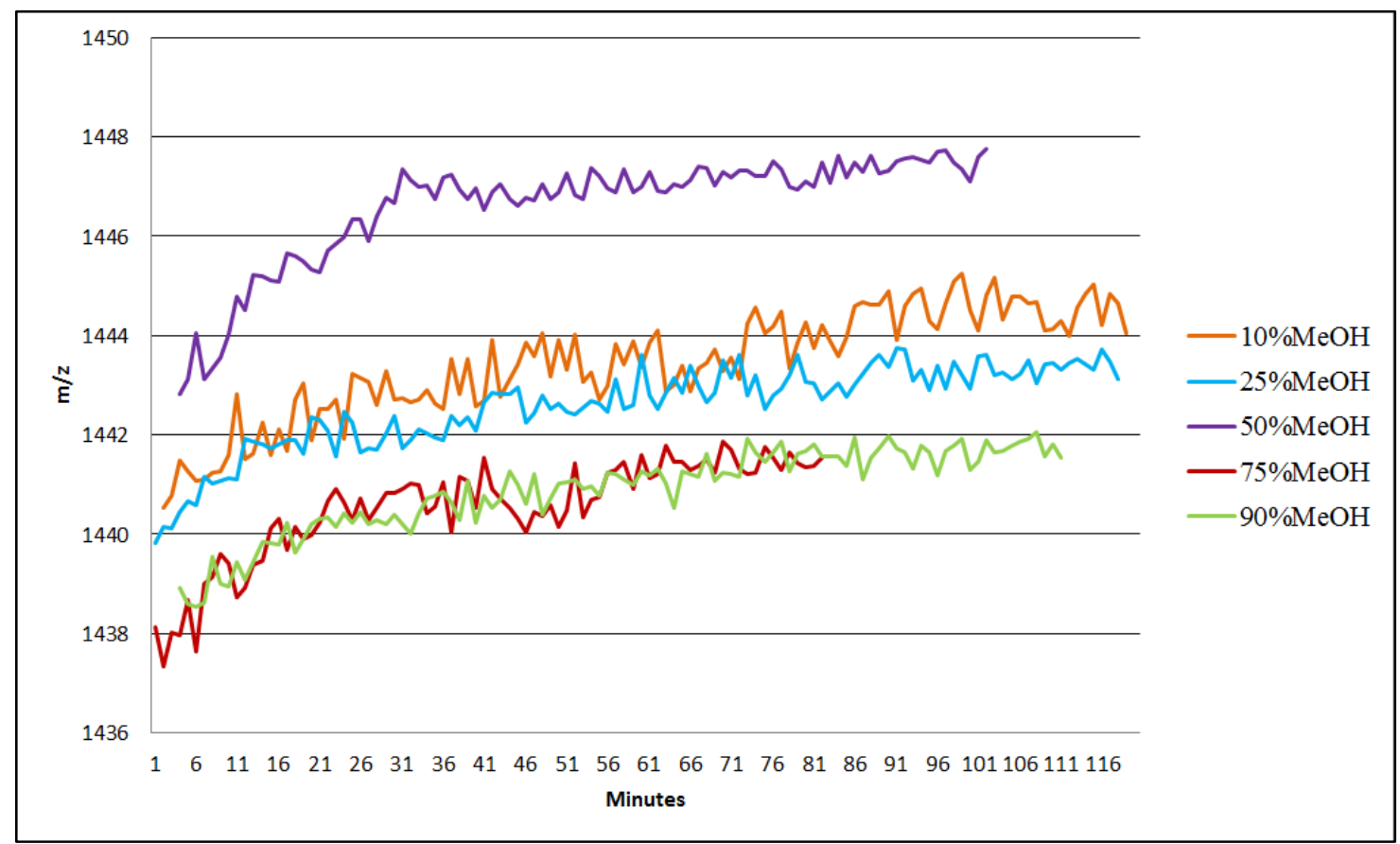

Fig. 21. Mass assignments of [d-ubiquitin $]^{+6}$ upon exposure to various concentrations of $\mathrm{MeOH} / \mathrm{D}_{2} \mathrm{O}$. 
Comparison of the deuterium exchange rates in ubiquitin showed distinct changes to the rate and degree of deuterium exchange as the concentration of methanol increased from 10 to $90 \%$, with the most significant changes occurring in the 25 to $75 \%$ methanol range. The degree of exchange is highest at 50\% methanol with mass shifts leveling off at approximately $1448 \mathrm{~m} / \mathrm{z}$ and the lowest degree of exchange residing at the 75 and $90 \%$ methanol concentrations with mass shifts leveling off at approximately $1442 \mathrm{~m} / \mathrm{z}$. Most notable are the similarities in the deuterium exchange rates and the overall mass shift of [d-ubiquitin] ${ }^{+6}$ in the 10 and $25 \%$ methanol solutions and those in the 75 and $90 \%$ methanol solutions.

\subsection{High Resolution Scan of d-Ubiquitin Peptide Fragments}

The high resolution mass analysis of chromatographically separated d-ubiquitin fragments focused on two charge states for each of the five preselected peptides. The high resolution scans, with a scan window of $15 \mathrm{~m} / \mathrm{z}$, were used to observe the mass shifts of peptide fragments produced from the peptic digest of deuterium labeled ubiquitin in various concentrations of methanol. The $\mathrm{m} / \mathrm{z}$ for each peptide was obtained for each charge state, analyzed, and plotted using the average masses of the entire chromatographic peak (Fig. 22). 


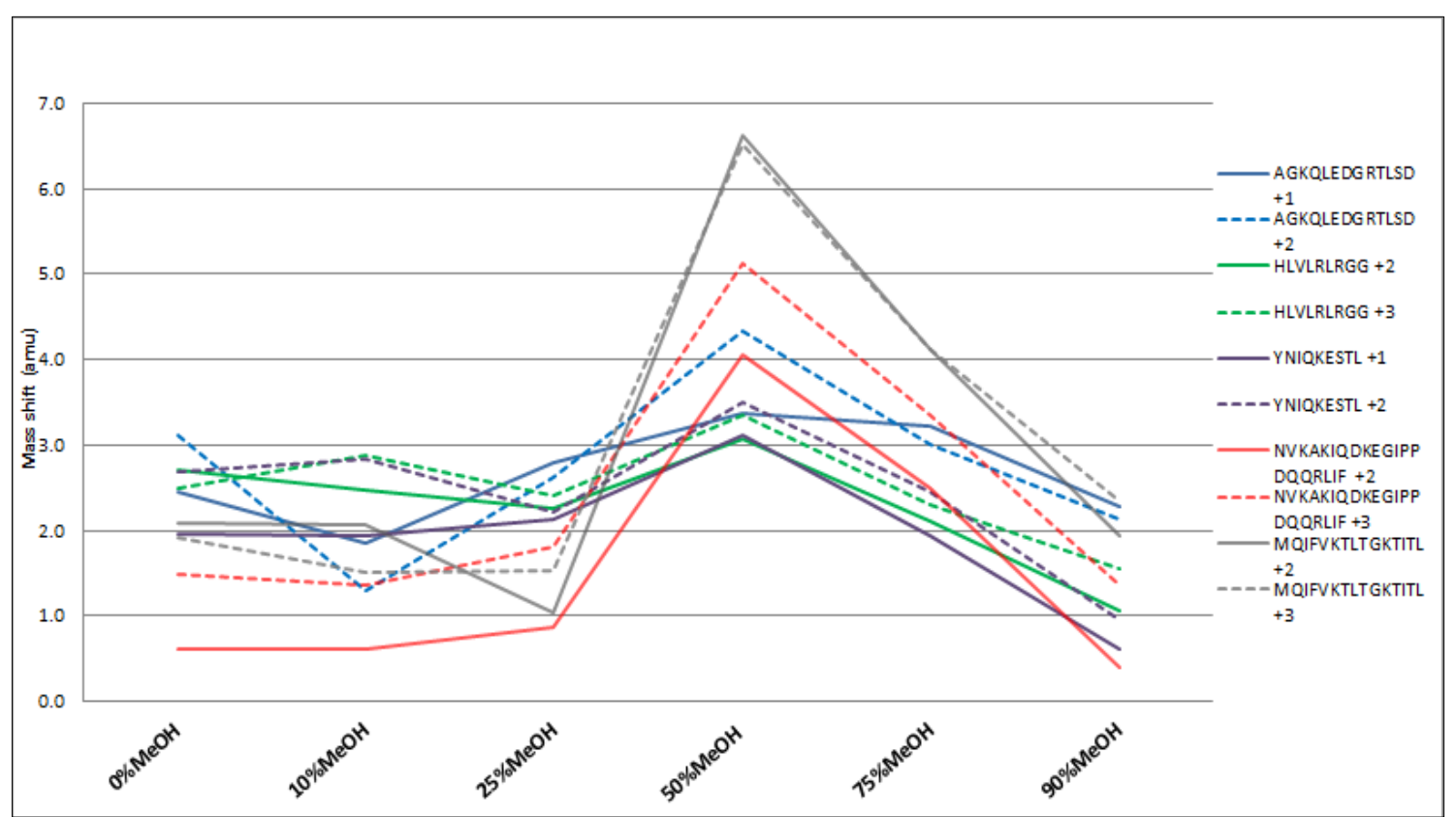

Fig. 22. Mass shifts for two charge states of the five preselected ubiquitn peptides from the peptic digestion of deuterium labeled ubiquitin in various concentrations of methanol/ $\mathrm{D}_{2} \mathrm{O}$. The mass shifts are relative to h-ubiquitin peptide mass measurements and reported in atomic mass units (amu).

The mass spectral analysis showed increases in mass for all of the five d-ubiquitin peptide fragments across all six solutions of varying concentrations of methanol. The mass increase was most prevalent in the 25 to $75 \%$ methanol range with all peptides experiencing some degree of positive mass shift and decreasing as the concentration of methanol reaches $90 \%$. The peptide MQIFVKTLTGKTITL exhibited the most increase, shifting more than 6 amu from its non-deuterated mass at 50\% methanol; a substantial increase in mass was also observed in peptide NVKAKIQDKEGIPPDQQRLIF with a shift of more than 4 amu. Minor overall increases in AGKQLEDGRTLSD, HLVLRLRGG and YNIQKESTL were observed with the most prevalent being in the 50\% methanol solutions. 
Examination of the overall increase in mass for each peptide can be shown to have close agreement with the ubiquitin conformational transitions suggested by Babu et al. ${ }^{15}$ and the deuterium exchange rates observed for ubiquitin. The collective analysis of each peptide fragment shows no overall increase in deuterium uptake until the concentration of methanol increases from 25 to $50 \%$ with a subsequent reduction as ubiquitin is exposed to $90 \%$ methanol. By examining all peptides collectively the transitions in ubiquitin conformation can be seen through the HiRes analysis of ubiquitin peptide fragments.

A clearer picture for the susceptibility of deuterium exchange in the ubiquitin peptides can be seen when averaging the mass shifts of the two peptide charge states used in the mass spectral analysis (Fig. 23). The degrees of mass shift for the d-ubiquitin peptides were clearly affected by methanol in solution showing distinct shifts in mass as the concentration of methanol changes. More evidence for the influence of methanol on ubiquitin can be seen in the relative position of each peptide when comparing the degree of mass shift (Fig. 24). 


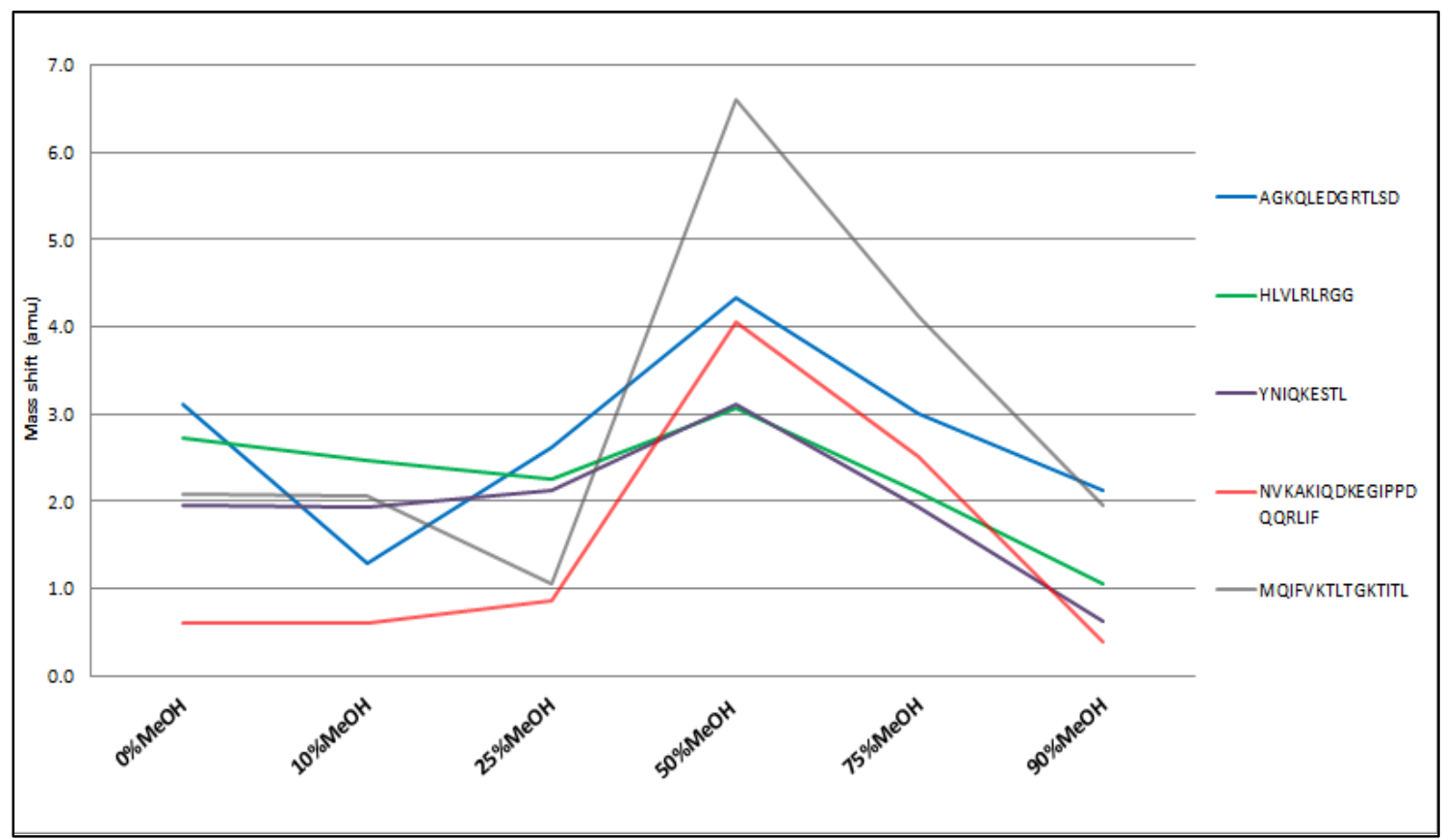

Fig. 23. The average mass shift between two observed charge states for each of the five preselected peptides from the peptic digestion of deuterium labeled ubiquitin in various concentrations of methanol/ $\mathrm{D}_{2} \mathrm{O}$. The mass shifts are relative to h-ubiquitin peptide mass measurements. Values are reported in atomic mass unit (amu).

\begin{tabular}{|c|c|c|c|c|c|}
\hline \multicolumn{2}{|l|}{ 0\%HeOH } & \multicolumn{2}{|c|}{$10 \% \mathrm{HeOH}$} & \multicolumn{2}{|c|}{ 25\%HeOH } \\
\hline AGKQLEDGRTLSD & 2.79 & HLVLRLRGG & 2.67 & AGKQLEDGRTLSD & 2.71 \\
\hline HLVLRLRGG & 2.60 & YNIQKESTL & 2.38 & HLVLRLRGG & 2.33 \\
\hline YNIQKESTL & 2.32 & MQIFVKTLTGKTITL & 1.78 & YNIQKESTL & 2.18 \\
\hline MQIFVKTLTGKTITL & 2.00 & AGKQLEDGRTLSD & 1.70 & NVKAKIQDKEGIPPDQQRLIF & 1.34 \\
\hline NVKAKIQDKEGIPPDQQRLIF & 1.05 & NVKAKIQDKEGIPPDQQRLIF & 0.98 & MQIFVKTLTGKTITL & 1.29 \\
\hline $50 \% \mathrm{MeOH}$ & & $75 \% \mathrm{Hel}$ & & 90\% & \\
\hline MQIFVKTLTGKTITL & 6.57 & MQIFVKTLTGKTITL & 4.12 & AGKQLEDGRTLSD & 2.20 \\
\hline NVKAKIQDKEGIPPDQQRLIF & 4.58 & AGKQLEDGRTLSD & 3.12 & MQIFVKTLTGKTITL & 2.15 \\
\hline AGKQLEDGRTLSD & 3.85 & NVKAKIQDKEGIPPDQQRLIF & 2.92 & HLVLRLRGG & 1.31 \\
\hline YNIQKESTL & 3.31 & HLVLRLRGG & 2.20 & NVKAKIQDKEGIPPDQQRLIF & 0.87 \\
\hline HLVLRLRGG & 3.20 & YNIQKEESTL & 2.19 & YNIQKESTL & 0.78 \\
\hline
\end{tabular}

Fig. 24. The mass shift values based on the average mass shift of the two observed charge states for each of the five preselected peptides. Values are reported in atomic mass unit (amu). 
The shifts in mass were greatest in 50\% methanol with the lowest mass shift at 3.20 amu for HLVLRLRGG, which is still a greater shift in mass observed in almost every other solution studied. The increase of masses at this concentration was even more profound when comparing the shifts in mass for MQIFVKTLTGKTITL and NVKAKIQDKEGIPPDQQRLIF in the 0-25\% solutions, where the greatest shifts had been 2.0 and $1.3 \mathrm{amu}$, respectively. In comparison the shift for MQIFVKTLTGKTITL had been 5.2 amu and 4.2 amu for NVKAKIQDKEGIPPDQQRLIF in the transition from 25 to $50 \%$ methanol. The $90 \%$ methanol solutions produced the lowest overall mass shift, restricting NVKAKIQDKEGIPPDQQRLIF and YNIQKESTL to the lowest rate of deuterium exchange in the experiment.

In overview, each peptide followed a distinct path of deuterium exchange; with MQIFVKTLTGKTITL and NVKAKIQDKEGIPPDQQRLIF demonstrating minor influences to mass from the presence of $0-25 \%$ methanol to dramatic shifts at $50 \%$ methanol, then a slow decrease in mass shift as the concentration increases to $90 \%$, to levels below those seen in the $0-25 \%$ methanol solutions. In contrast, the deuterium uptake for peptides YNIQKESTL, HLVLRLRGG, AGKQLEDGRTLSD was shown to be the least influenced by the greater presence of methanol. 


\subsection{Conclusion}

\subsection{Circular Dichroism Experiments}

Circular dichroism analysis of ubiquitin in various concentrations of methanol showed a clear increase in the helical structure of ubiquitin as the concentration of methanol reached 90\%; these results were consistent with observations described by Babu et al. ${ }^{15}$ and studied by Wilkinson et al. ${ }^{13}$ In conducting the complimentary analysis, this experiment indicated changes in the secondary structure of ubiquitin in various concentrations of methanol, with clear transitions in ubiquitin conformation that closely matched the exchange rate analysis conducted by Babu et al. ${ }^{15}$ and Wright et al. ${ }^{21,22}$ In addition, the independent $\mathrm{CD}$ analysis suggested that $\beta$-sheet character in the native state of ubiquitin is lost as the concentration of methanol increases to $50 \%$.

\subsection{Deuterium Exchange Rate Analysis}

The deuterium exchange rate analysis conducted on ubiquitin in various concentrations of methanol was in close agreement with observations reported by Babu et al. ${ }^{15}$ and Wright et al. ${ }^{21,22}$ The complimentary rate analysis showed three distinct regions of exchange for varying concentrations of methanol, with 10 and $25 \%$ methanol having the slowest rates of deuterium exchange, 75 and $90 \%$ methanol having the highest rates of exchange, and solutions of 50\% methanol falling in-between. The three distinct groupings of ubiquitin exchange rates are consistent with the conformational transitions observed in the circular dichroism analysis. 


\subsection{High Resolution Scan of d-Ubiquitin Peptide Fragments}

The three-dimensional structure of ubiquitin has been studied through X-ray

diffraction experiments ${ }^{19,31}$ to determine the native structure of ubiquitin, revealing a hydrophobic core with a 3.5 turn $\alpha$-helix at residues 23-34 (IENVKAKIQDKE) and four $\beta$-strands. Two of these $\beta$-strands were shown to be in parallel and form an inner sheet at residues 1-7 (MQIFVKTLT) and 64-72 (ESTLHLVLR). The other two $\beta$-strands were antiparallel and form an outer structure, incorporating residues 11-17 (KTLTLEV) and 40-44 (QQRLI).

Comparison of the five peptides used for HX experiments and the location of secondary structures in the native state of ubiquitin (Fig. 25) showed little correspondence with the sites of peptic cleavage, voiding any determination of deuterium uptake to the secondary structure. It is important to note that the five peptides used for analysis were selected based on their relative abundance, and no criteria had been set to select peptides that may have closely matched residues with specific structural elements in the native state. 


\begin{tabular}{|c|c|c|c|c|c|c|c|c|c|c|c|}
\hline \multicolumn{11}{|c|}{ UBIQUITIN } & \\
\hline \multicolumn{2}{|c|}{ MQIFVKTLTGKTITL } & \multicolumn{2}{|c|}{ EVEPSDTIE } & \multicolumn{3}{|c|}{ NVKAKIQDKEGIPPDQQRLIF } & $\overline{A G K}$ & KQLEDGRTLSD & YNIQKESTL & HLVLRLRG & \\
\hline \multicolumn{2}{|c|}{$1-15$} & \multicolumn{2}{|c|}{$16-23$} & \multicolumn{3}{|c|}{$25-45$} & \multicolumn{2}{|r|}{$46-58$} & $59-67$ & \multicolumn{2}{|l|}{$68-76$} \\
\hline MQIFVKTLT & \begin{tabular}{|l|l} 
LTG & $K 1$ \\
\end{tabular} & TTLTLEV & EPSI & & IENVKAKIQDKE & GIPPD & QQRLI & FAGKQLEDGR & TLSDYNIQK & ESTLHLVLR & LRGG \\
\hline $1-7$ & $8-10$ & $11-17$ & $18-$ & & $23-34$ & $35-39$ & $40-44$ & $45-$ & & $64-72$ & $73-76$ \\
\hline
\end{tabular}

Fig. 25. Diagram for the representation of ubiquitin native state structure and the five preselected ubiquitin peptides used in the hydrogen/deuterium exchange experiments. Above) The 5 peptides selected for the bottom-up deuterium-exchange experiment in green. Below) The ubiquitin sequence showing different structures in the native state of ubiquitin and the associated residues; blue represent $\beta$-sheets in the inner structure, $\beta$-sheets in the outer structure in aqua, and $\alpha$-helix in red. Residues showing reverse turns in red font.

The amounts of deuterium exchange for each peptide in the bottom-up HX experiment show the most significant uptake in peptide MQIFVKTLTGKTITL followed by peptide NVKAKIQDKEGIPPDQQRLIF. In the native structure, peptide sequence MQIFVKTLTGKTITL has been shown to contain two $\beta$-strands residing in different locations of the three-dimensional structure of ubiquitin. The peptide sequence NVKAKIQDKEGIPPDQQRLIF was shown to contain the sole $\alpha$-helix and a portion of one of the outer residing $\beta$-strands. In the hydrogen/deuterium exchange experiments, neither of these peptides was shown to have any significant change in deuterium uptake until the methanol solution reached a concentration of $50 \%$.

The peptide sequences AGKQLEDGRTLSD and YNIQKESTL, despite a few random turns and partial inner $\beta$-sheet structure in YNIQKESTL, were shown to have little regular structure in the ubiquitin native state. These peptides had little changes to the degree of deuterium exchange as a result of increases in the concentration of methanol. In analyzing the amount of deuterium exchange in the two peptides, it can be 
stated that each peptide shows the least change from its native state conformation to the highly helical structure of ubiquitin in $90 \%$ methanol. The explanation for the relatively modest changes in deuterium uptake may be linked to the random turns and lack of overall structure of these peptide sequences in their native state. It is quite possible that as the conformation of ubiquitin changes to a more helical state these peptides, with an already ambiguous structure of random turns in the native state, require little manipulation to achieve the well-defined structured $\alpha$-helix found in the $90 \%$ methanol solutions. The main argument for minimal hydrogen exchange resides in the preservation of hydrogen bonds within the secondary structure of AGKQLEDGRTLSD and YNIQKESTL, thus blocking any exchange with these hydrogen-bonded amides to deuterium.

The peptide sequence HLVLRLRGG in the native state of ubiquitin contains a partial inner $\beta$-sheet structure and is absent of structure in half of the sequence. The most important feature of this sequence is it includes the N-terminus of ubiquitin and is roughly seen to follow the same exchange levels seen in AGKQLEDGRTLSD and YNIQKESTL.

In the bottom-up hydrogen/deuterium exchange experiments the peptides MQIFVKTLTGKTITL and NVKAKIQDKEGIPPDQQRLIF proved to have the most significance in using the acquired data to derive some conformational insight into local changes on the ubiquitin protein. It can be seen that these two peptides contain three of the four $\beta$-strands in the native state ubiquitin protein. Of these three $\beta$-strands, two of 
them lie in the outer $\beta$-sheet in contact with the solvent. CD spectral analysis suggested elimination of $\beta$-sheet character as the concentration of methanol increased beyond $25 \%$, ultimately ending with very prevalent helical structure in the entire protein at $90 \%$ methanol concentrations, consistent with observations made by Babu et al. ${ }^{15}$ implying that the two $\beta$-sheets residing on the outer structure of ubiquitin were converted to a structure with high helicity. The unfolding of the outer $\beta$-strands can be seen as the cause for high exchange of deuterium at the amide backbone due to the breaking of all hydrogen bonds at the amide backbone upon degradation or unfolding of the $\beta$-strands.

The unfolding of $\beta$-sheets could be seen as having the most significant effect for higher degrees of deuterium exchange; however the peptides YNIQKESTL and HLVLRLRGG have both been shown to contain an inner $\beta$-strand but do not show the same changes in deuterium uptake, possibly indicating that the $\beta$-strands located within the ubiquitin core structure are more stable and therefore experience less exchange of deuterium than those of the outer $\beta$-sheet. It is also worth noting that peptide sequence MQIFVKTLTGKTITL has inner and outer $\beta$-sheets in its native state, possibly explaining the highest degree of exchange seen in all five peptides.

\subsection{Bottom-up Hydrogen/Deuterium Exchange Analysis of Ubiquitin}

The bottom-up hydrogen/deuterium exchange analysis was better able to illustrate the methanol-induced transition of ubiquitin, showing a native state structure at $25 \%$ methanol and then quickly denaturing at 50\% methanol, through what Babu et al. ${ }^{15}$ describes as an intermediary transition state. Data acquired in this experiment suggested 
intermediary transitions were the result of denaturation at the $\beta$-sheets, and the residues involved in the most dynamic regions reside at 11-17 (KTLTLEV) and 40-44 (QQRLI).

Although this thesis first set out to study areas of high dynamicity as a way to investigate active sites of proteins, it may be possible to study areas of increased structural stability as well. In this experiment it can be said that the $\beta$-sheets in ubiquitin are doing exactly what $\beta$-sheets in a protein maybe intended to do, offer structural stability to the entire protein. In this case the $\beta$-sheets may be seen as very strong stabilizing structures in the protein by holding the native state constant in a very extreme environment, in solutions of at least $25 \%$ methanol. It can also be said that once the $\beta$ sheets structure was denatured the entire structure of the protein began to unfold. 


\subsection{Future Work}

The project attempted to observe the conformational changes in ubiquitin by focusing on the relative mass changes of five ubiquitin peptides after undergoing a bottom-up approach to hydrogen/deuterium exchange mass spectrometry. It is important to note that there is still more research required in order to gain a clearer picture into the change in conformation of ubiquitin as it is exposed to greater concentrations of methanol.

One clear limitation of this research was the instrumentation used in obtaining the mass spectra. It is clear that mass spectral analysis of proteins requires a much greater degree of resolution than that presented in this work. The requirement for a single point $\mathrm{m} / \mathrm{z}$ to track the mass shift is one of the major limitations of this work. In using a higher performing mass spectrometer, it may be possible to overcome this limitation and actively monitor mass shifts more accurately, not to mention an ability to monitor the mass shifts of a complete protein isotopic distribution rather than a weighted average indicator.

In the research presented, the concentrations of methanol used were 10, 25, 50,75 , and $90 \%$ giving a low resolution illustration of the conformational changes experienced by ubiquitin as it is exposed to greater concentrations of methanol. One issue this

research overlooked was the transition state reported by Babu et al. ${ }^{15}$ which described a very dynamic change to the ubiquitin structure at the 30 to $50 \%$ methanol concentration range. This research did not look into this area and it would be appropriate for further 
research to conduct greater analysis at this level possibly taking smaller incremental steps in concentration, than the broad steps in concentration used in this research.

The thesis tries to find areas of increased flexibility in the protein by denaturing it with methanol, it was hoped that places of activity may become denatured more easily and first to take up deuterium. This may not have been the case in this work as it may have been able to see areas of increased stability much easier. Employing multiple solvents in the analysis may offer different pathways of denaturation of the protein. Any future work should consider using multiple solvents for manipulating the protein structure in different ways, for example, non-polar solvents can be used to try and destabilize hydrophobic regions within the protein which have been shown to be the site of many protein active sites.

It is understood that any deuterium that has exchanged on to the amide backbone of a protein inherently becomes likely to back exchange with hydrogen and thus eliminate any mass shift in the protein. It is therefore extremely important to take any additional steps to ensure a minimal amount of deuterium back exchange. This requirement is most important in the chromatographic separation of peptides in the bottom-up analysis of hydrogen/ deuterium exchange. It is therefore recommended that any future work attempt to develop procedures that would ensure attainment of $\mathrm{pH} 2.7$ and the stable retention of $0^{\circ} \mathrm{C}$ during the deuterium quenching state to reduce the possibility of deuterium loss at the amide backbone. 


\section{References}

1. Chiti, F.; Dobson, C.M.; Protein Misfolding, Functional Amyloid and Human Disease. Annu. Rev. Biochem., 2006, 75, 333-366.

2. Marcon, G.; Plakoutsi, G.; Canale, C.; Relini, A.; Taddei, N.; Dobson, C. M.; Ramponi, G.; Chiti, F. J. Amyloid Formation from HypF-N under Conditions in which the Protein is Initially in its Native State Mol. Biol. 2005, 347, 323-335.

3. Anfinsen, C.B. The Formation and Stabilization of Protein Structure. $J$. Biochem., 1972, 128, 737-749.

4. Katta, V.; Chait, B.T. HD Exchange ESIMS: A Method for Probing Protein Conformational Changes in Solution. J. Am. Chem. Soc., 1993, 115, 6317-6321.

5. Bai, Y.; Milne, J.S.; Mayne, L.; Englander, S.W. Primary Structure Effects on Peptide Group Hydrogen Exchange. Proteins, 1993, 17, 75-86.

6. Hoofnagle, A.N.; Resing, K.A.; Ahn, N.G. Protein Analysis by Hydrogen Exchange Mass Spectrometry. Annu. Rev. Biophys. Biomol. Struct., 2003, 32, 125

7. Zhang, Z.; Smith, D.L. Determination of Amide HXMS: A New Tool for Protein Structure Elucidation. Protein Sci., 1993, 2, 522-531.

8. Department of Chemistry and Chemical Biology at Northeastern University. The Egen Laboratory. http://www.hxms.neu.edu/research/tutorial_theory.html (accessed Feb 19, 2013).

9. Connely, G.P.; Bai, Y.; Jeng, M.; Englander, S.W. Isotope Effects in Peptide Group Hydrogen Exchange. Protein, 1993, 17, 87-92. 
10. Wales, T.E.; Engen, J.R. Hydrogen Exchange Mass Spectrometry for the Analysis of Protein Dynamics. Mass Spec. Rev., 2006, 25, 158-170.

11. Busenlehner, L.S.; Armstrong, R.N. Insights Into Enzyme Structure and Dynamics Elucidated by Amide H/D Exchange Mass Spectrometry. Arch. Biochem. Biophys., 2005, 433, 34-46

12. Englander, S.W.; Mayne, L. Protein Folding Studied Using Hydrogen Exchange Labeling Two Dimensional NMR. Annu. Rev. Biophys. Biomol. Struct., 1992, 21, 243-265.

13. Wilkinson, K. D.; Mayer, A.N. Alcohol-Induced Conformational Changes of Ubiquitin. Arch. Biochem. Biophys., 1986, 250, 390-399.

14. Hirota, N.; Mizuno, K.; Goto, Y. Cooperative $\alpha$-helix Formation of $\beta$ lactoglobulin and Meittin Induced by Hexafluoroisopropanol. Protein Sci., 1997, $6,416-421$.

15. Babu, K.R.; Moradian, A.; Douglas, D.J. The Methanol-Induced Conformational Transitions of $\beta$-Lactoglobulin, Cytochrome $c$, and Ubiquitin at Low pH: A Study by Electrospray Ionization Mass Spectormetry. J. Am. Chem. Soc., 2001, 12, 317328.

16. Konermann, L.; Douglas, D.J. Unfolding of Proteins Monitored by Electrospray Ionization Mass Spectrometry: A Comparison of Positive and Negative Ion Modes. Biochemistry., 1997, 36, 12296-12302.

17. Hamuro, Y.; Coales, S.J.; Southern, M.R.; Nemeth-Cawley, J.; Stranz, D.D.; Griffin, P.R. Rapid Analysis of Protein Structure and Dynamics by 
Hydrogen/Deuterium Exchange Mass Spectrometry. J. Biomol. Tech., 2003, 14, $171-182$.

18. Nath, N.; Shadan, S. The Ubiquitin System. Nature Insight, March 2009, pp 421467.

19. Vijay-Kumar, S; Bugg, C.E.; Wilkinson, K.D.; Cook, W.J. Three-dimensional Structure of Ubiquitin at 2.8 A Resolution Proc. Natl. Acad. Sci.

U.S.A., 1985, 82, 3582-3585.

20. Wikipedia. Ubiquitin Search: Creating author Rogerdodd. https://en.wikipedia.org/wiki/Ubiquitin (accessed Feb 19, 2013.)

21. Wright, P.J.; Zhang, J.; Douglas, D.J. Conformations of Gas-Phase Ions of Ubiquitin Produced from Two Different Solution Conformations. J. Am. Chem. Soc., 2008, 19, 1906-1913.

22. Wright, P.J. Fragmentation of Gas Phase Ions of Ubiquitin Produced from Different Solution Conformations in a 3D Ion Trap. Poster Presentation, Varian, Inc., Wood Dale IL, 2001.

23. Kamarati, Y.O.; Ohji, S.; Konno, T.; Seki, Y.; Soda, K.; Kataoka,M.; Akasaka, K. The Compact and Expanded Denatured Conformations of Apomyoglobin in the Methanol-Water Solvent. Protein Sci., 1999, 8, 873-882.

24. Konnermann, L.; Douglas, D.J. Acid-Induced Unfolding of Cyto. $c$ at Different Methanol Concentrations ESIMS Monitors Tertiary Structure. Biochemistry, 1997, 36, 12296-12302. 
25. Loo, J.A.; Orgorzalek-Loo, R.R.; Udseth, H.R.; Edmonds, C.G.; Smith, R.D. Solvent-Induced Conformational Changes of Polypeptides Probed by ESIMS. Rapid. Commun. Mass Spec., 1991, 5, 101-105.

26. Glasoe, P.K.; Long, F.A. Use of Glass Electrodes to Measure Acidities in Deuterium Oxide. J. Phys. Chem., 1960, 64, 188-190.

27. Paloshoff, M.H. Determining the Specificity for Pepsin for Proteolytic Digestion. Master's Thesis, Northeastern University, Boston, MA, 2008.

28. Piper, D.W.; Fenton, B.H. pH stability and Activity Curves of Pepsin with Special Reference to Their Clinical Importance. Gut., 1965, 6, 506-508

29. Feng, L.; Orlando, R.; Prestegard, J.H. Mass Spectrometry Assisted Assignment of NMR Resonances in ${ }^{15} \mathrm{~N}$ Labeled Proteins. J. Am. Chem. Soc., 2004, 19, 14377-14379.

30. Jaremko, L.; Jaremko, M.; Pasikowski, P.; Cebrat, M.; Stefanowicz, P.; Lisowski, M.; Artym, J.; Zimecki, M.; Zhukov, I.; Szewczuk, Z. The Immunosuppressive Activity and Solution Structures of Ubiquitin Fragments. Biopolymers., 2009, 91, 423-431.

31. Vijay-Kumar, S; Bugg, C.E.; Wilkinson, K.D.; Cook, W.J. Structure of Ubiquitin Refined at 1.8 A Resolution. J. Mol. Biol., 1987, 194, 531-44. 